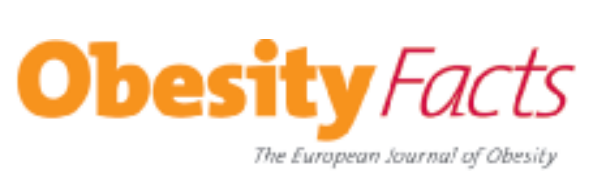

Abstracts

Obes Facts 2009;2:255-268

Published online: September 4, 2009

\title{
Nordic Obesity Meeting
}

\section{ABSTRACTS}

Guest Editors

\section{E.T. Aasheim,}

M. Svendsen,

M. Pollestad Kolsgaard,

S. Tonstad, Oslo;

J. Hjelmesæth, Tønsberg, Norway

Invited Speakers

Original Abstracts

Author Index p. 256

258

268
September 17-18, 2009

Oslo, Norway

Norwegian Association for the Study of Obesity www.nfff.no

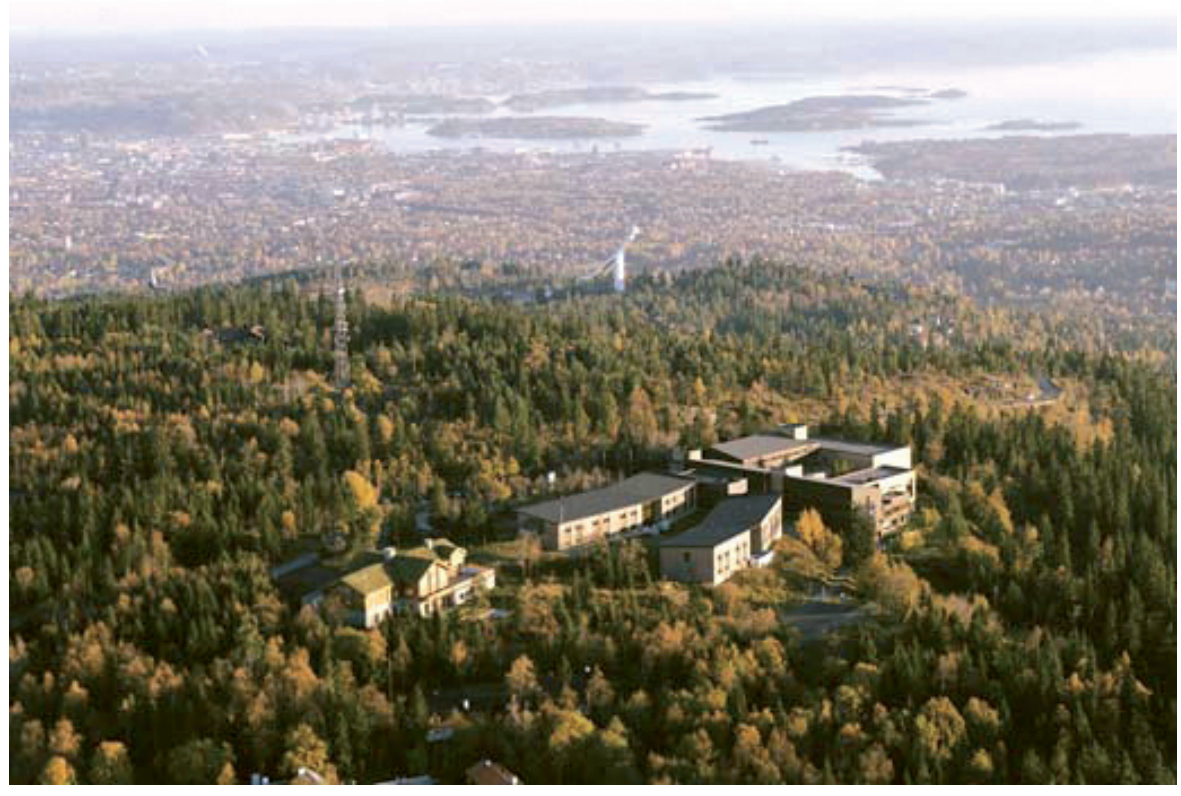

\section{EASO}




\section{Obesity Facts \\ The European fournal of Obesity}

Abstracts

Obes Facts 2009;2:256-267

\section{Invited Speakers}

\section{RS1}

\section{Obesity and Type 2 Diabetes in Norway: New Data from the HUNT Study}

Holmen, J.; Midthjell, K.; Krokstad, S.; Lingaas Holmen, T. HUNT Research Centre, Department of Public Health and General Practice, Norwegian University of Science and Technology (NTNU)

Background: Nord-Trøndelag County $(n=130,000)$ in middle Norway has a CVD mortality similar to Norway as a whole, and is used for epidemiological studies since the 1980'ies (The Nord-Trøndelag Health Study, HUNT). The purpose of this paper was to study changes in overweight, obesity and diabetes over a period of approximately 11 years. Methods: In 1995-97 all citizens in Nord-Trøndelag aged $\geq 13$ years were invited to a health survey (HUNT 2), and this was repeated in 2006-08 (HUNT 3). Height, weight, hip and waist circumference were measured according to the same protocol, and extensive health data were collected using several questionnaires. Blood samples were taken in all aged $>20$, in addition to a number of clinical measurements. Results: Mean BMI $\left(\mathrm{kg} / \mathrm{m}^{2}\right)$ increased in all age groups in both genders, except in elderly women. The increase was largest in men, and especially in younger age groups. The obesity prevalence (BMI $\geq 30)$ in men aged $\geq 20$ increased from $14.4 \%$ in HUNT 2 to $22.5 \%$ in HUNT 3 , ranging from $13.8 \%$ in age group $20-29$ to $25.2 \%$ in age group $60-69$. Corresponding figures in women were $18.6 \%$ in HUNT 2 and $23.5 \%$ in HUNT 3, ranging from $13.8 \%$ in age group $20-29$ to $30.7 \%$ in age group $70-79$. Also in age group 13-19 mean BMI and the obesity prevalence increased markedly. The prevalence of known diabetes in women aged $\geq 20$ increased from $2.9 \%$ in HUNT 2 to $3.8 \%$ in HUNT 3, and in men from $3.1 \%$ in HUNT 2 to $5.0 \%$ in HUNT 3, with greatest increase in age group 50-69. The increase in body weight and diabetes prevalence occurred during a period of time when several other CVD risk factors and CVD mortality declined. Conclusions: The general trend of increased body weight has not levelled off, and has now been strongest in men and in younger age groups. The prevalence of known diabetes increased in parallel, but several other CVD risk factors and the CVD mortality declined during the same period. This association is not yet fully understood.

\section{RS2}

\section{Prevention of Obesity}

\section{Heitmann, B.L.}

Research Unit for Dietary Studies, Institute of Preventive Medicine, Copenhagen University Hospitals, Denmark. BLH@ipm.regionh.dk

Obesity is still on the increase worldwide, with immediate as well as long-term health consequences. The easy accesses to fattening foods, as well as an increasing sedentary lifestyle, are the two main factors generally accepted to be the causes of the continuing increase in the obesity occurrence. However, among adults the evidence that changing food and activity habits can prevent obesity is generally lacking, and among children results are limited and conflicting. Indeed, even recent reviews of the current literature on obesity prevention among children seems to be reaching opposite conclusions despite being based on results from the same body of scientific papers.

It is evident from several studies, that the propensity to gain weight varies greatly between individuals, even under equal conditions of food- and energy supply and energy expenditure, and hence that obesity is manly a genetic condition expressed when an interplay of lifestyle, environmental, social, cognitive and cultural factors are operating.

Therefore prevention of obesity is not straightforward and the disappointing results from previous interventions may be viewed in this light. Prevention interventions may be more successful when applied to high-risk groups or individuals than to subsets of the general population.

Conflicts of interest: None.

Funding: Danish Medical Research Councils

\section{RS3}

Increasing Physical Activity in a Population Perspective.

\section{Can It Be Done?}

Fogelholm, M.

Academy of Finland, Helsinki, Finland

The behavior of physical activity can be seen as a function of internal motivation (intention) and external circumstances. The higher the internal drive for physical activity is, the less the external circumstances affect an individual's behavior. In contrast, for those with weaker motivation for physical activity, the surrounding physical and social environment may play a significant role. Increasing physical activity of the population by changing the environment is demanding. First, all ages from childhood to very old age should be taken into consideration. Second, both daily commuting activities, as well as more sporty exercises should be promoted. In most cases, the changes in the environment should make physical activity more enjoyable (e.g. by attractiveness of the environment), accessible (e.g. shorter distances) and cheap. Some operations may also decrease the competitiveness of an alternative behavior. Regulations to make driving by car a less attractive alternative are good examples (e.g. toll roads, expensive parking, very little parking spaces, etc.). The most important decisions concerning environmental planning and physical activity are taken in local communities. State subsidies may increase the motivation in local communities to invest on e.g. neighborhood sports facilities.

\section{RS4}

\section{Gene-Environment Interactions}

\section{Pietiläinen, $K$.}

Obesity Research Unit, Helsinki University Central Hospital, Helsinki, Finland Finnish Twin Cohort Study, Department of Public Health, University of Helsinki, Helsinki, Finland. kirsi.pietilainen@helsinki.fi

The acquired component of complex traits is difficult to dissect in humans. Obesity is one such disorder, where the metabolic and molecular consequences emerge from complex interactions of genes and environment.

We have used a special study design of 'clonal controls', rare monozygotic twins selected from two national cohorts (FinnTwin12 and FinnTwin16) of nearly 5000 twin pairs to represent pairs extremely discordant for obesity, to expose obesity-induced changes in biological pathways in fat tissue and recently also in muscle. The twins were carefully studied for their body fat content and distribution and glucose metabolism. Lipidomics profiling of both serum and adipose tissue was performed by liquid chromatography/mass spectrometry, and global gene expression profiling of abdominal subcutaneous adipose tissue samples by Affymetrix chip array.

The obesity-discordant monozygotic twin pairs $\left(4-10 \mathrm{~kg} / \mathrm{m}^{2}\right.$ BMI difference, $\mathrm{n}=14$ in the first set of studies) allowed us to dissect acquired lifestyle effects from the genetic predisposition to aberrant metabolic characteristics of obesity. Many metabolic variables were very similar in the monozygotic co-twins. This, together with the difficulty of even finding obesity-discordant monozygotic twins indicated that genetic contribution for the development of obesity is clear. However, we also showed that the acquired component in obesity is strong, and characterized by several metabolic disturbances independent of genetic effects. In particular, we have shown that the obese co-twins' adipose tissue was less energy efficient, had a $47 \%$ reduction in mitochondrial DNA copy number, significant downregulation of genes in the mitochondrial amino acid metabolism pathways and upregulation of multiple proinflammatory pathways in global transcriptomic arrays (PLoS Med 5(3): e51). Importantly, the observed aberrations in adipose tissue correlated closely with liver fat accumulation, whole body insulin resistance and hyperinsulinemia, early events of acquired obesity in these 'healthy' young adults.

Our findings show that although both genes and environment play a role, several of the disturbances that have been characterized in obesity are not due to genes but due to lifestyle. Such results warrant exploration of the environmental actions to prevent the development of obesity and its related complications. Pietiläinen K H, Naukkarinen J, Rissanen A, Saharinen J, Ellonen P, Keränen H, Suomalainen A, Gotz A, Suortti T, Yki-Järvinen H, Oresic M, Kaprio J, Peltonen L: Global transcript profiles of fat in monozygotic twins discordant for BMI: pathways behind acquired obesity. PLoS Med 2008;5:e51.

Pietiläinen K H, Sysi-Aho M, Rissanen A, Seppälä-Lindroos A, Yki-Järvinen H, Kaprio $\mathrm{J}$, Oresic M: Acquired obesity is associated with changes in the serum lipidomic profile independent of genetic effects - a monozygotic twin study. PLoS ONE 2007;2:e218.

\section{KARGER}

Fax +497614520714

Information@Karger.de www.karger.com (c) 2009 S. Karger GmbH, Freiburg

Accessible online at:

www.karger.com/ofa 
RS6

\section{Benefits of $5 \%$ Weight Reduction}

\section{Lindström, J.}

Diabetes Prevention Unit, National Institute for Health and Welfare, Helsinki, Finland

Overweight and obesity are common in the modern society and in general less than $50 \%$ of European citizens have body mass index below 25 which denotes 'normal weight'. Excess accumulation of body fat is known to increase CVD risk factors, such as hypertension, dyslipidemia, and especially type 2 diabetes. Furthermore, there is evidence supporting the relationship between obesity and increased risk of some cancers. Other comorbidities of overweight and obesity include e.g. sleep-disordered breathing and sleep apnoea, depression, dementia, and decreased quality of life.

Convincing evidence on the effect of reduction of excess body fat on risk factors, symptoms, and comorbidities related to obesity comes from bariatric surgery. Surgery is an option for a small subgroup of morbidly obese patients For the general population, more traditional methods to manage body weight are relevant. Sustained long-term weight reduction is challenging. However, there is some evidence supporting the beneficial effect of a relatively modest weight reduction of $5 \%$ even among people who after weight loss still can be classified as overweight or obese. The Finnish Diabetes Prevention Study DPS, among others, has indicated that the effect of modest weight reduction may be especially significant on factors related to insulin resistance and, consequently, risk of developing type 2 diabetes. These results will be shown in the presentation.

\section{RS8}

Integrated Treatment of Obesity and Other Cadiovascular Risk

\section{Factors}

Tonstad, S.

Department of Preventive Cardiology, Oslo University Hospital Ullevål, Oslo, Norway

Many of the health consequences of obesity are related to cardiovascular disease (CVD). CVD risk factors should be addressed systematically in obese patients, and patients should be offered optimal treatment for dyslipidemia, smoking, hypertension and diabetes. However, undertreatment of these risk factors is common as shown by data from over 1400 referrals for obesity to the Ullevaal Preventive Cardiology Dept. at Oslo University Hospital. Assessing CVD risk in young to middle aged individuals (e.g. below age 50 years) with obesity is a possible barrier to treatment. Calculators like SCORE do not include some metabolic risk factors like high triglycerides/low HDL cholesterol and yield low absolute risk scores for younger individuals. Furthermore, though individual considerations are recommended in estimating risk, it may be difficult for physicians to know how to implement in practice. In Norway, official 2009 guidelines for preventing CVD suggest that metabolic syndrome be considered in individuals below age 40. Yet another barrier is that treating some CVD risk factors could worsen obesity, for example, smoking cessation or certain drugs used for diabetes. Future studies need to address how to assess risk in obesity, how to optimalize risk factor treatment and new treatments for smoking cessation. I will illustrate how we approach the obese patient with CVD risk factors at our clinic in Oslo.

Conflicts of interest: None relevant to this abstract.

Funding: None.

\section{RS9}

\section{Surgical Treatment of Obesity}

\section{Näslund, $E$.}

Department of Clinical Sciences, Danderyd Hospital, Karolinska Institutet, Stockholm, Sweden

The most effective treatment of obesity is surgery. The most frequently performed surgical procedure is gastric bypass (GBP). GBP results in a significant sustained weight loss and ameliorates co-morbid disease associated with obesity such as type 2 diabetes mellitus (T2DM). This has prompted a movement to rename bariatric surgery metabolic surgery and it has been suggested that patients with T2DM with lower BMI than $35 \mathrm{~kg} / \mathrm{m}^{2}$ should be offered bariatric surgery. This remission of T2DM occurs early after surgery before any significant weight loss has occurred. This suggests a procedure specific, weight independent effect on glucose homeostasis. Possible mechanisms for this procedure specific effect on T2DM of GBP surgery may be enhanced stimulation of the lower gut with enhanced release of incretin hormones such as glucagon-like peptide-1 (hindgut theory), exclusion of the duodenum (foregut theory), compromised ghrelin secretion, altered insulin sensitivity and yet known effects. Research aimed at assesing the relative importance of these effects and attempting to indentify other mechanisms may not only improve surgical design but also to indentify novel targets for diabetes treatment. Novel surgical procedures and endoscopic devices are currently in development and being tested for the treatment of T2DM.

Conflicts of interest: None.

Funding: Swedish Medical Research Council, Funds of the Karolinska Institutet and Stockholm County Council.

\section{RS10}

\section{Obesity Surgery in Adolescents: Results from AMOS, a Swedish Nationwide Study}

Olbers, $T$.

Sahlgrenska University hospital, Gothenburg, Sweden/ Imperial College, London

Introduction: The burden of severe obesity in the adolescent includes both the social stigmata as well as metabolic risks. Hereby we present initial results from a nationwide Swedish controlled study- AMOS- to assess the safety and feasibility of lap gastric bypass in morbidly obese adolescents Methods: Eighty-one adolescents (13 to 18 years) were included. The adolescents were operated at Sahlgrenska between 2006 and 2009. Inclusion criteria included a history of failed conservative treatment and a BMI $>1=$ 40 or $>/=35$ with co-morbidities. Follow up visits are scheduled for one, two, five and ten years postop. We identify four conservatively controls to each operated subject in a nationwide register. Primary end point is weight loss and weight stability, secondary endpoints include metabolic and cardio vascular risk factors, anthropometry and quality of life status. Results: Inclusion weight was in mean $133 \mathrm{~kg}$ (SD $22.1 \mathrm{~kg}$ ); BMI $45.5 \mathrm{~kg} / \mathrm{m}^{2}$ (SD $6 \mathrm{~kg} / \mathrm{m}^{2}$ ). So far 53 subjects had their one year follow and 19 had their two year control. Two years postop subjects showed a mean weight of $95.4 \mathrm{~kg}$ (SD $17.8 \mathrm{~kg}$ ) and a significant total weight loss of $30.9 \%($ SD $9.3 \%)(\mathrm{p}=0.000)$. Mean BMI two years after surgery was $31.3 \mathrm{~kg} / \mathrm{m}^{2}\left(\mathrm{SD} 4.6 \mathrm{~kg} / \mathrm{m}^{2}\right)(\mathrm{p}=0.000)$; mean excess BMI loss $71.1 \%$ (SD $21.9 \%$ ). Two years after surgery subjects showed significantly lower value of fasting insulin $(\mathrm{p}=0.000)$ and insulin two hour after OGTT ( $\mathrm{p}=0.022$ ). Significant improvement was, two years after surgery, further found for blood pressure, LPK, LDL, HDL, TG, super sensitive CRP, ApoB and regarding anthropometry measurements (waist, hip, neck, arm). The treatments were overall well tolerated among the adolescents and there were only two minor perioperative complications. Conclusion: These data indicates that lap Gastric Bypass can achieve equally effective results in adolescents as in adults regarding weight loss and metabolic improvements up to two years after surgery. Further follow up regarding quality of life and long term results compared to control group is however required before general recommendations.

Conflicts of interest: Travel grants and lecture fees från J\&J och Covidien.

\section{RS11}

\section{Obesity Surgery in Nordic Countries}

\section{Søvik, T.T.}

Department of Gastrointestinal Surgery, Oslo University Hospital Aker

Obesity surgery was pioneered in the Nordic countries during the 1990s by Swedish surgeons. The Swedish Obese Subjects matched cohort study, a landmark in this field, has imparted important knowledge on the long-term effects of surgically induced weight loss. Laparoscopic bariatric surgery was simultaneously established at several Norwegian hospitals, upon government request by 2004. Bariatric surgery was already available in Iceland and Denmark by this time. Similar surgical programs are increasingly being established in Finland.

The Roux-en-Y gastric bypass is the most commonly performed bariatric procedure in the Nordic countries presently. Alternative available operations include biliopancreatic diversion with duodenal switch, sleeve gastrectomy and gastric banding. These operations are technically challenging and require advanced surgical skills. Serious adverse events are rare but potentially fatal. Previous studies have suggested that a surgeon needs to have performed about 100 operations to reach a low and stable morbidity rate. This highlights the importance of a team of dedicated surgeons, high procedural volumes, and close monitoring of the patient postoperatively.

This presentation will focus on the total surgical volume, and the type of operations performed for the surgical treatment of morbid obesity in Nordic countries. Establishing a bariatric surgical program will be described - exemplified by the results of laparoscopic gastric bypass surgery at the Oslo University Hospital Aker. The perioperative results and the effect of the procedural volume will be discussed. Strategies for quality control and research will also be presented. 


\section{Original Abstracts}

OP01

Type 2 Diabetes and Prediabetes are Independent Predictors of Obstructive Sleep Apnea in Extremely Obese Subjects

Fredheim, J.M. ${ }^{1,2}$; Hofs $\varnothing$, D. ${ }^{1}$; Vegsgaard, K.M. ${ }^{2}$; Rollheim, J. ${ }^{\text {; }}$ Hjelmesæth, $J^{1}$

${ }^{1}$ Morbid Obesity Center, Vestfold Hospital Trust, Tønsberg, Norway

${ }^{2}$ Ear, Nose and Throat Department, Vestfold Hospital Trust, Tønsberg,

Norway

Purpose: To explore the association between obstructive sleep apnea (OSA) and glucose tolerance in extremely obese $\left(B M I \geq 40 \mathrm{~kg} / \mathrm{m}^{2}\right)$ subjects. Methods: One hundred and thirty seven ( 99 females) consecutive, extremely obese patients underwent a somnography with Embletta ${ }^{\circledR}$ and a 2 hour oral glucose tolerance test (OGTT). Obstructive sleep apnea (OSA) was defined as having an apnea-hypopnea index (AHI) $\geq 5$ events/hour. Glucose tolerance was classified into three categories; Normal glucose tolerance [fasting serum glucose (FSG) $<5.6 \mathrm{mmol} / \mathrm{l}$ and 2 hours serum glucose (2HSG) $<7.8 \mathrm{mmol} / \mathrm{l}]$ prediabetes (FSG between 5.6 and $6.9 \mathrm{mmol} / \mathrm{l}$ and/or $2 \mathrm{HSG}$ between 7.8 and $11.0 \mathrm{mmol} / \mathrm{l}$ ) and type 2 diabetes (FSG $\geq 7.0 \mathrm{mmol} / 1,2 \mathrm{HSG} \geq 11.1 \mathrm{mmol} / \mathrm{l}$ or previously known diabetes). To compare differences between groups, independent sample t-test was used for continuous data, whilst $\chi^{2}$ was used for categorical data. Multiple logistic regression analysis was used to identify independent determinants of OSA. Results: The patients had a mean (SD) age of 43 (11) years and BMI $47(6) \mathrm{kg} / \mathrm{m}^{2}$. Males had significantly higher mean (SD) AHI than females, 29 (25) vs. 12 (17) events/hour, $\mathrm{p}<0.001$. OSA was prevalent in $29(81 \%)$ men and in $54(54 \%)$ women, $\mathrm{p}=0.008$. Thirty nine (29\%) subjects had normal glucose tolerance, 58 (42\%) had prediabetes and $40(29 \%)$ had type 2 diabetes. Among the patients with normal glucose tolerance $33 \%$ had OSA, while $67 \%$ of the prediabetic and $78 \%$ of the type 2 diabetic patients had OSA, $\mathrm{p}<0.001$. After adjusting for age, gender and BMI, both prediabetes and type 2 diabetes were associated with OSA, odds ratios $2.91(1.03,8.21), p=0.044$ and $4.49(1.34,15.05), p=0.015$, respectively. Conclusions: Type 2 diabetes and prediabetes are independently associated with OSA in extremely obese subjects.

Conflict of Interest: None Disclosed.

Funding: Jan Magnus Fredheim is a PhD Fellow at the Morbid Obesity Center, Vestfold Hospital Trust, Tønsberg, Norway. Dag Hofs $\varnothing$ has received unrestricted educational grants from Novo Nordisk A/S, South-Eastern Norway Regional Health Authority and Vestfold Hospital Trust.

\section{OP02}

\section{Serum Creatinine Is Inversely Associated with Type 2 Diabetes in Morbidly Obese Women and Men}

Hjelmesæth, J. ${ }^{1}$; Nordstrand, N. ${ }^{1}$; Hofsø, D. ${ }^{1}$; Hager, $H_{.}{ }^{2}$; Røislien, J., ${ }^{1,3}$ Hartmann, A. $^{4}$

${ }^{1}$ Morbid Obesity Center, Vestfold Hospital Trust, Tønsberg,

${ }^{2}$ Department of Clinical Chemistry, Vestfold Hospital Trust, Tønsberg,

${ }^{3}$ Department of Biostatistics, Institute of Basic Medical Sciences, University of Oslo, ${ }^{4}$ Department of Medicine, Rikshospitalet University Hospital, University of Oslo, Norway

Purpose: A recent study of middle-aged lean Japanese men showed that low serum creatinine was associated with higher risk of type 2 diabetes. We aimed to validate this finding in a population of morbidly obese Caucasian women and men. Methods: A total of 1,017 consecutive morbidly obese Caucasian patients, 687 women, all with an estimated glomerular filtration rate $>60 \mathrm{ml} /$ $\min / 1.73 \mathrm{~m}^{2}$, were included in the analyses. Independent samples t-test were used to compare groups. Univariate and multiple logistic regression analyses were implemented to assess the associations between serum creatinine and type 2 diabetes before and after adjustments for confounding factors. Hume's equations were used for calculating lean body mass in women (W) and men $(\mathrm{M}): \mathrm{W}=[0.29569 \times$ weight $(\mathrm{kg})]+[0.41813 \times$ height $(\mathrm{cm})]-43.2933$ and $\mathrm{M}$ $[0.32810 \times$ weight $(\mathrm{kg})]+[0.33929 \times$ height $(\mathrm{cm})]-29.5336$. Results: The patients with type 2 diabetes $(n=262 ; 26 \%)$ had a significantly higher mean (SD) age than those without diabetes $(n=755) ; 48$ (11) vs. 40 (12) years, $\mathrm{p}<0.001$. In contrast, mean serum creatinine was significantly lower in patients with type 2 diabetes; 64 (12) vs. 66 (11) micromol/l, p=0.012, and lean body mass did not differ significantly; 69.2 (11.3) vs. $68.4(10.6) \mathrm{kg}, \mathrm{p}=0.308$. Univariate logistic regression analysis showed that serum creatinine was inversely associated with type 2 diabetes (odds ratio 0.983 [95\% CI 0.971-0.996], $\mathrm{p}=0.008$ ). The significant negative association between serum creatinine and type 2 diabetes was not attenuated after adjustments for age, gender, family history of diabetes, lean body mass, current smoking, weekly alcohol intake, insulin resistance (HOMA), inflammation, serum magnesium, serum potassium, serum uric acid, hypertension, antihypertensive drugs (thiazides and ACE-inhibitors/ A2RB) and albuminuria (adjusted odds ratio 0.973 [95\% CI 0.954-0.993], $\mathrm{p}=0.008)$. Conclusions: Serum creatinine is inversely associated with type 2 diabetes in extremely obese Caucasian women and men. Each micromol/l increase in creatinine was associated with $3 \%$ lower odds of type 2 diabetes. Low skeletal muscle mass or glomerular hyperfiltration might partly explain our findings, but causative mechanisms remain to be shown.

Conflict of interest: None Disclosed.

Funding: Dag Hofsø has received unrestricted educational grants from Novo Nordisk A/S, South-Eastern Norway Regional Health Authority and Vestfold Hospital Trust.

\section{OP03}

\section{Fasting Plasma Glucose in the Screening for Type 2 Diabetes in Morbidly Obese Subjects}

Hofs $\varnothing$, D. ${ }^{1}$; Jenssen, T.2, ${ }^{3}$ Hager, H. ${ }^{4}$; Røislien, J. ${ }^{1,5}$; Hjelmesæth, J. ${ }^{1}$ ${ }^{1}$ Morbid Obesity Center, Vestfold Hospital Trust, Tønsberg ${ }^{2}$ Department of Medicine, Rikshospitalet University Hospital, Oslo ${ }^{3}$ Institute of Clinical Medicine, University of Troms $\emptyset{ }^{4}$ Department of Clinical Chemistry, Vestfold Hospital Trust, Tønsberg ${ }^{5}$ Department of Biostatistics, Institute of Basic Medical Sciences, University of Oslo, all authors Norway

Purpose: Higher mortality rates among morbidly obese subjects are mainly explained by obesity related co-morbidities such as type 2 diabetes. Bariatric surgery ameliorates diabetes, and obese diabetic subjects will therefore probably have the greatest benefits of bariatric surgery. Screening for diabetes prior to surgical referral is therefore crucial. The objective of the present study was to assess the effectiveness of various screening strategies based on fasting plasma glucose (fPG) followed by a diagnostic oral glucose tolerance test (OGTT), for detecting undiagnosed diabetes in morbidly obese subjects. Methods: During a three years period 1,253 morbidly obese (BMI $\geq 40$ or $\geq 35$ $\mathrm{kg} / \mathrm{m}^{2}$ with a weight-related co-morbidity) Caucasian subjects (women $67 \%$ ) were consecutively recruited to this cross-sectional study. Among nondiabetic subjects, 70\% (670/961) underwent an OGTT. Type 2 diabetes was diagnosed in subjects with an fPG level $\geq 7.0 \mathrm{mmol} / \mathrm{L}$ and/or a 2 hour plasma glucose ( $2 \mathrm{hPG}$ ) level $\geq 11.1 \mathrm{mmol} / \mathrm{L}$. Results: In the whole population, $31 \%$ had type 2 diabetes of which $8 \%$ were screen-detected. Eighty percent $(53 / 66)$ of those with unknown diabetes were identified by a diabetic fPG concentration. In subjects with nondiabetic fPG concentrations $(n=617)$, elevating the fPG cutoff value from $5.2 \mathrm{mmol} / \mathrm{L}$ to the WHOs recommended value of $6.1 \mathrm{mmol} / \mathrm{l}$ for referring to an OGTT, reduced both the percent of the population needing an OGTT (from 78 to $23 \%$ ) and the sensitivity for detecting a diabetic $2 \mathrm{hPG}$ concentration (from 100 to $77 \%$ ). Only $7 \%$ (10/142) of the patients with an fPG value between 6.1 and $6.9 \mathrm{mmol} / \mathrm{L}$ had a diabetic $2 \mathrm{hPG}$ concentration. Following WHOs recommendations, 95\% (63/66) of all subjects with unknown diabetes would be identified after performing a confirmatory OGTT in $21 \%$ $(142 / 670)$ of those without known diabetes. Conclusions: Fasting plasma glucose was effective in identifying subjects with unknown type 2 diabetes in morbidly obese subjects. A large proportion of the population would need an OGTT to identify the majority of the few remaining diabetic cases.

Conflicts of interest: None Disclosed.

Funding: Dag Hofs $\varnothing$ has received unrestricted educational grants from Novo Nordisk A/S, South-Eastern Norway Regional Health Authority and Vestfold Hospital Trust.

\section{OP04}

\section{Dietary Intervention in Metabolic Syndrome:}

\section{Short- and Long-Term Effects on Abdominal Obesity}

\section{Korneeva, O.N.; Drapkina, O.M.}

I.M. Sechenov Moscow Medical Academy, Moscow, Russian Federation

Purpose: Our aim was to assess prospectively the short- and long-term effects of a calorie-reduced diet on obesity anthropometric measures like bodymass index (BMI), waist circumference (WC), waist-to-hip ratio (WHR) and compliance to the diet in men and women with MS. Methods: 60 MS patients were enrolled according to IDF criteria (36 men) with average age $48 \pm 13$ years. $B M I$ at baseline $=33.4 \pm 4.9 \mathrm{~kg} / \mathrm{m}^{2}$ both sexes; $\mathrm{WC}=115.3 \pm 11.3 \mathrm{~cm}$ men, $=108.8 \pm 9.6 \mathrm{~cm}$ women; WHR $=1.02 \pm 0.06$ men,$=1.00 \pm 0.07$ women. We compared obesity anthropometric changes in two diet programs: short-term hypo-caloric diet of $1800 \mathrm{kcal}$ per day during 3 weeks supervised by hospital physicians; after that diet was home-based and completed by the participants on their own during 6 months. Results: At 3 weeks, in supervised group there 
were significant reductions in all obesity anthropometric measures in both sexes $(\mathrm{p}<0.0003)$; however, men have achieved larger reduction in $\mathrm{WC}$ and WHR than women $(\Delta \mathrm{WC}$ men $=4.6 \pm 1.7 \mathrm{~cm}$ vs. $\Delta \mathrm{WC}$ women $=3.7 \pm 2.1 \mathrm{~cm}$ $\Delta$ WHR men $=0.03 \pm 0.01$ vs. $\Delta$ WHR women $=0.027 \pm 0.01)$. At 6 month unsupervised patients had less WC and WHR reductions compare with 3 weeks data (WC men $112.1 \pm 10.7 \mathrm{~cm}$ vs. $110.6 \pm 10.4 \mathrm{~cm}$; WC women $103.0 \pm 6.9 \mathrm{~cm}$ vs $104.7 \pm 9.3 \mathrm{~cm} ;$ WHR men $=1.0 \pm 0.05$ vs $0.99 \pm 0.05 ;$ WHR women $=0.96 \pm 0.05$ vs. $0.98 \pm 0.06$ ). Compliance to the home-based diet was related to sex (women better than men) and was associated with greater reduction in WC and WHR in women. At 6 months home-based diet men had a significant increase in abdominal obesity compare 3 weeks diet $(\Delta$ WC 3 weeks-6months $=-1.44 \pm 2.9$ $\mathrm{cm}$ men, $\mathrm{p}=0.02 ; \Delta \mathrm{WHR}=-0.014 \pm 0.02, \mathrm{p}=0.003)$. Conclusion: In this prospec tive study supervised short-term hypo-caloric program is more effective than home-based 6 months diet. We demonstrated the predictive value of gender in outcomes: men had greater reductions in WC and WHR in short-term supervised program, but due to the less men compliance to the long-term homebased diet, women had greater reduction in WC and WHR after 6 months.

\section{OP05}

\section{Dietary Intake of Protein Is Associated with Weight Loss among} Obese Subjects with Components of Metabolic Syndrome

Svendsen, M. ${ }^{1}$; Pedersen, T.R. ${ }^{1}$; Holme, I. ${ }^{1}$; Tonstad, S. ${ }^{1}$; Klemsdal, T.O.

${ }^{1}$ Department of Preventive Cardiology, Oslo University Hospital Ullevål, Norway

Purpose: The optimal composition of macronutrients in weight loss diets is not elucidated. We aimed to study how the reported intake of carbohydrate, fat and protein were associated with weight loss after three months of dietary treatment for weight reduction. Methods: Subjects were 158 men and women aged $51 \pm 7$ years with a BMI of $32.9 \pm 2.8 \mathrm{~kg} / \mathrm{m}^{2}$ included in a randomized, parallel study comparing two moderately energy restricted diets $(-500 \mathrm{kcal})$. The effects of the diets; a low glycemic load diet (LGL; 35-40 energy percent fat 30-35 energy percent carbohydrate, 25-30 energy percent protein) and a low fat diet (LF; $<30$ energy percent fat, 55-60 energy percent carbohydrate, $\sim 15$ energy percent protein) on weight loss and metabolic risk factors have been reported elsewhere. In the present study, dietary counselling was given by a nutritionist in individual and group sessions for a total of four times. Dietary intake was assessed by a seven-day dietary record three months after randomization. Results: After three months, no difference in weight loss between the groups was seen $(-5.1 \pm 3.4 \mathrm{~kg}$ versus $-4.4 \pm 3.7 \mathrm{~kg}, \mathrm{P}=0.9$ in the $\mathrm{LGL}$ and LF groups, respectively). Thus, the groups were pooled for the present analyses. In a multivariate analysis with difference in weight as the dependent variable and energy percent from protein, carbohydrate and fat as independent variables, energy percent from protein was the only variable associated with weight loss $\left(\mathrm{R}_{\text {adj }}^{2}=0.027, \mathrm{P}=0.022\right)$. A graded response in weight loss was seen with increasing energy percent from protein, $\mathrm{P}$ for trend $=0.034$ (Table 1 ).

Table 1 Weight loss in percentiles of protein intake

\begin{tabular}{llll}
\hline & $\mathrm{N}$ & $\begin{array}{l}\text { Weight loss } \\
\text { (mean) }\end{array}$ & $95 \% \mathrm{CI}$ \\
\hline Energy percent protein $\leq 17.1$ & 33 & $-3.6 \mathrm{~kg}$ & $-4.6 \mathrm{~kg},-2.6 \mathrm{~kg}$ \\
Energy percent protein $17.2-18.5$ & 32 & $-5.5 \mathrm{~kg}$ & $-6.6 \mathrm{~kg},-4.4 \mathrm{~kg}$, \\
Energy percent protein $18.6-20.3$ & 30 & $-4.2 \mathrm{~kg}$ & $-6.0 \mathrm{~kg},-2.4 \mathrm{~kg}$ \\
Energy percent protein $20.4-23.0$ & 32 & $-4.5 \mathrm{~kg}$ & $-5.5 \mathrm{~kg},-3.5 \mathrm{~kg}$ \\
Energy percent protein $\geq 23.1$ & 31 & $-6.1 \mathrm{~kg}$ & $-7.4 \mathrm{~kg},-4.8 \mathrm{~kg}$ \\
\hline
\end{tabular}

Conclusion: In dietary counselling for weight reduction emphasize of increasing protein intake may enhance weight loss in obese subjects with components of metabolic syndrome.

Conflicts of interest: None disclosed.

Funding: This study was supported by a grant from the Norwegian National Research Council.

\section{OP06}

\section{Obesity and Male Reproductive Function}

Witczak, O.; Aschim, E.L.; Andersen, J.M.; Skram, I.V.;

Windju, S.; Sandbu, R.*; Hjelmesæth, J. *; Haugen, T.B.

Faculty of Health Sciences, Oslo University College, Oslo, Norway

*Morbid Obesity Centre, Vestfold Hospital Trust, Tønsberg, Norway

In the last decades there may have been a decline in semen quality. Likewise, the proportion of overweight $\left(\mathrm{BMI}>25 \mathrm{~kg} / \mathrm{m}^{2}\right)$ and obese $(\mathrm{BMI}>30$ $\mathrm{kg} / \mathrm{m}^{2}$ ) individuals is increasing. Obesity has been found to be a risk factor for female infertility. Studies have indicated that obese men often have poor semen quality and require increased time to achieve pregnancy. Furthermore, overweight in men has been associated with reduced levels of testosterone, LH and FSH and elevated levels of oestrogen. To date, no studies have investigated the effect of weight reduction on male fertility.

We are investigating if excess body weight has a negative impact on several male reproductive characteristics, and if weight loss due to dietary, surgical or lifestyle changes can improve the reproductive function. Male participants with BMI above $27 \mathrm{~kg} / \mathrm{m}^{2}$ who are planning to lose weight, are recruited to the study. Blood pressure, percent body fat, general health status, medication, smoking, physical activity are recorded. Semen analysis (sperm concentration, motility, morphology and vitality) is performed according to WHO recommendations. The serum levels of FSH, LH, inhibin B, SHBG, oestradiol, testosterone, insulin, leptin, ghrelin and adiponectin are measured. In addition, serum lipids (total cholesterol, LDL, HDL and TG), micro CRP, blood glucose and glycated haemoglobin are determined. Fatty acid composition in plasma and sperm phospholipids is measured by gas chromatography. All the analyses are performed before and after weight loss.

Our preliminary results based on 31 men before weight loss, showed a negative correlation between sperm concentration and FSH (rho $=-0.444$ $\mathrm{p}=0.026$ ), and percent vital cells and oestradiol ( $\mathrm{rho}=-0.541, \mathrm{p}=0.005)$. Almost $50 \%$ of the participants had increased oestradiol levels. We found a negative correlation between SHBG and BMI ( $\mathrm{rho}=-0.413, \mathrm{p}=0.040)$, and a reduction in serum testosterone by $0.524 \mathrm{nmol} / \mathrm{L}$ per unit increase in BMI when adjusting for age $(\mathrm{p}=0.044)$. Half of the study population had metabolic syndrome. If our study indicates that weight loss improves hormone values and semen quality, weight reduction should be recommended to obese men with fertility problems.

Conflicts of interest: None.

Funding: This study is supported by Oslo University College.

\section{OP07}

Circulating Concentrations and Dietary Intake of Vitamin D in Norwegian Morbidly Obese Patients

Johnson, L.K. ${ }^{1,2}$; Hofsø, D. ' Oppedal, B. ${ }^{1}$; Aasheim, E.T. ${ }^{3}$;

Tanbo, T. ${ }^{2}$; Holven, K.B. ${ }^{4}$; Hjelmesæth, J. ${ }^{1}$

${ }^{1}$ Morbid Obesity Center, Vestfold Hospital Trust, Tønsberg, Norway

${ }^{2}$ Rikshospitalet University Hospital, Oslo, Norway

${ }^{3}$ Aker University Hospital, Oslo, Norway

${ }^{4}$ University of Oslo, Department of Nutrition, Institute for Basic Medical

Sciences, Oslo, Norway

Purpose: Morbid obesity is associated with vitamin D-deficiency. We aimed to investigate whether dietary intake of vitamin D and season of blood sampling are associated with vitamin D-levels in morbidly obese patients. Methods: A total of 153 weight loss seeking morbidly obese patients (112 women and 41 men) underwent structured dietary interviews, including a validated comprehensive food-frequency questionnaire. Fasting serum concentrations of 25-hydroxyvitaminD [25(OH)D] were measured. We defined $25(\mathrm{OH}) \mathrm{D}$ levels $<50 \mathrm{nmol} / \mathrm{L}$ as low, and $\geq 50 \mathrm{nmol} / \mathrm{L}$ as adequate. Mann-Whitney test, independent samples t-test and chi-square test were used in the statistica analyses. Results: In total 82 patients had low vitamin D levels and 71 had adequate levels. Further results are shown in the table:

\begin{tabular}{llll}
\hline & $\begin{array}{l}\text { Low } \\
\text { vitamin D level } \\
\mathrm{N}=82\end{array}$ & $\begin{array}{l}\text { Adequate } \\
\text { vitamin D level } \\
\mathrm{N}=71\end{array}$ & p-value \\
\hline Male/Female [n (\%)] & $\begin{array}{l}30(73.2 \%) / 52 \\
(46.4 \%)\end{array}$ & $11(26.8 \%) / 60(53.6 \%)$ & $0.006^{1}$ \\
Age (years) & $42(11.7)$ & $45.2(9.7)$ & $0.077^{2}$ \\
Weight $(\mathrm{kg})$ & $136.6(23)$ & $122(17.8)$ & $<0.001^{2}$ \\
BMI $\left(\mathrm{kg} / \mathrm{m}^{2}\right)$ & $46.4(6.8)$ & $42.8(4.9)$ & $<0.001^{2}$ \\
Waist circumference $(\mathrm{cm})$ & $136.8(13.9)$ & $127.6(12.2)$ & $<0.001^{2}$ \\
Vit D intake $(\mu \mathrm{g} /$ day) & $8.3(4.7-11.7)$ & $8.8(5.5-12.9)$ & $0.567^{3}$ \\
*Vit D supplement, yes/no & $9(50 \%) / 73(54.1 \%)$ & $9(50 \%) / 62(45.9 \%)$ & $0.941^{1}$ \\
\hline
\end{tabular}

${ }^{1}$ Chi-Square Test. [Data given as number (\%)]

${ }^{2}$ Independent samples t-test. [Data given as mean (SD)]

${ }^{3}$ Mann-Whitney U test. [Data given as median (IQR)]

*Reported supplementation of 5-10 $\mu \mathrm{g}$ vit. D/day

Conclusion: Vitamin D intake and season of blood sampling did not differ significantly between patients with low and adequate vitamin D levels. How- 
ever, men had a significantly higher prevalence of low vitamin D levels. Anthropometric measures of central and overall obesity were associated with vitamin D levels.

Conflicts of interest: None disclosed.

Funding: Line Kristin Johnson has received unrestricted educational grants from National Resource Centre for Women's Health, Rikshospitalet University Hospital, Norway.

\section{OP08}

Prevalence of Overweight and Obesity in 7-9 Year Old Swedish Boys and Girls

Sjöberg, A. ${ }^{1}$; Lissner, L. ${ }^{1}$; Moraeus, L. ${ }^{1}$; Poortvliet, E. ${ }^{2}$; Al-Ansari, U. ${ }^{2} ;$ Yngve, A. $^{2}$

${ }^{1}$ Sahlgrenska School of Public Health and Community Medicine, University of Gothenburg and ${ }^{2}$ Unit for Public Health Nutrition, Karolinska Institutet, Sweden

Purpose: Over the last 20 years prevalence of childhood overweight and obesity has increased in Sweden as in other parts of the world. This finding is, however, based on results from regional and local studies and there is lack of information about the prevalence in a nationally selected sample. Secondly, most of the data is based on routine measurements performed by schoo health care and include variation in quality of equipment, methods and clothing. In the current study, prevalence data for a national sample of children in school year 1 and 2 was gathered. The study was part of the WHO European Childhood Obesity Surveillance Initiative (COSI) in which nationally representative anthropometric data for children in 14 European countries are collected. Methods: A total of 220 schools were proportionally randomly selected from the national registry of schools. All were invited and 92 schools agreed to participate and were included. Participating schools were found to be representative of Sweden and of the originally sampled schools, with regard to being public or independent and to type of municipality. Our field staff visited each school on one day and all attending pupils in grades 1 and 2 were invited to participate. Heights and weights were measured using standardised methods and study specific field equipment. BMI was calculated and weight classification was performed using IOTF definitions for overweigh and obesity and definition for underweight as proposed by Cole 2007 . Results: The preliminary results for 4201 children suggest that around $17 \%$ were overweight or obese, $3 \%$ obese, while $7 \%$ were underweight. Prevalence of overweight and obesity was lowest in metropolitan and suburban municipalities, and highest in commuter municipalities. Also in large cities and in the remaining types of municipalities, prevalence of overweight and obesity was on a higher level than in more urbanised areas. The data presented here are not final, but based on results available at the time this abstract was submitted. Conclusions: We observed that the prevalence of overweight including obesity varies by type of community and that prevalence seems to be lower in metropolitan areas than in the rest of the country. These results confirm the importance of nationally representative surveys.

Conflicts of interest: None.

Funding: Swedish Council for Working life and Social Research (Projects: EpiLife, COSI and CLOE) and Swedish Research Council.

\section{OP09}

\section{The Silent Kitchen Revolution}

Bechensteen, B.; Graff-Iversen, S.; Benth, J.S.; Vogt, H.; van Roy, B.; Haugstvedt, K.T.S.; Nafstad, I.T.; Saxegaard, K.;

\section{Andersen, L.F.}

Centre for health promotion, Akershus University Hospital, Oslo, Norway

Purpose: The aim of this study was to assess the feasibility of group counselling of parents of overweight children without involving the children themselves, except for measurements. Hereby we present feasibility experiences and changes in measurements of the children after one year. Material and Methods: This study is a three year intervention project. Through the municipality health service we recruited 46 children ( 28 girls, 18 boys) with overweight or obesity (4-11 years old, mean 7.5 years) and their parents. The parents participated in six group sessions of three hours during the fist year These sessions were led by a dietician and a coach/physiotherapist. The parents had the possibility to see a psychiatrist. We aimed to conduct a semiexperimental trial which included recruiting a 'usual care' control group of overweight children, but did not succeed in spite of several efforts. The main targets were changes in direction of less energy dense food, increased intake of fruits, vegetables and of physical activity, reduced portion size, consumption of sugar sweetened beverage and of television/video viewing. At the start of the project and after one year the children met with a doctor to measure weight and height, and the parents filled in a food frequency questionnaire and a formula reporting on the child's activity. The parents also evaluated the project anonymously. Results and Interpretation: Thirty eight children and their parents returned to the doctor after one year (17.4\% drop-out). Mean BMI $\left(\mathrm{kg} / \mathrm{m}^{2}\right)$ values at the start and after one year were 26.4 and 26.8 respectively. BMI z-score was significantly reduced from 3.2-3.0 $(\mathrm{p}<0.001)$ The parents reported significantly reduced intake of fries, hamburgers, hot dogs, kebabs, sugar-sweetened beverage and juice, and significant increase of organised physical activity. On the question Were the items in focus (of counselling group), actually important for you? the mean of the parents' answers were 8.6 at a scale from 1 (not important) to 10 (very important). Concerning the intervention, we conclude that treatment of childhood obesity with the parents as agents of changing seems to be feasible. The lack of comparison group is a serious limitation with respect to interpretation of the result.

\section{OP10}

\section{Ethnic Differences in Improved BMI-z Score after a One-Year} Hospital-Public Health Nurse Combined Intervention

\section{Pollestad Kolsgaard, M.L. ' ; Joner, G. ${ }^{1,2}$; Tonstad, S. ${ }^{3,4}$;}

\section{Andersen, L.F.}

${ }^{1}$ Department of Pediatrics, Oslo University Hospital, Ullevål, Oslo, Norway

${ }^{2}$ Institute of Health Management and Health Economy, University of Oslo,

Norway

${ }^{3}$ Department of Preventive Cardiology, Oslo University Hospital, Ullevål,

Oslo, Norway

${ }^{4}$ Department of Nutrition, Institute of Basic Medical Sciences, University of Oslo, Norway

Purpose: In 2004 the 'Oslo Adiposity Intervention Study' was initiated by the Department of Pediatrics at Oslo University Hospital, Ullevaal as a combined hospital/public health system approach. The aim of the present paper was to compare the effect of the intervention on body mass index (BMI) zscores between Norwegians and the major other ethnic groups included in the intervention program, that is children with Pakistani, Tamil and Turkish origins. Methods: Children and adolescents aged 7-18 years and diagnosed as overweight or obese by their medical doctor were referred to the outpatient pediatrics care clinic consisting of a team of pediatrician, nutritionist and testing personnel. From February 2004 until December 2008 a total of 257 girls and boys with Norwegian, Pakistani, Tamil and Turkish origins joined the study. Participants and their parents met with pediatrician and/or nutritionis 4 times in the course of the first year. Individualized counseling regarding diet and physical activity was given, and the participants got the opportunity to take part in physical activity. To enhance compliance, visits with the public health nurse at the local public health station were scheduled between the hospital-based consultations. The public health nurses tried to motivate the children and parents to follow the advices given at the hospital. At baseline and one-year of follow-up the participants underwent a physical examination and provided fasting blood samples. Height and weight were measured at baseline, after 6 months and 1 year. Of the total, data was available for 163 participants who completed 1 year of follow up. Changes in weight status were evaluated with BMI z-scores. Results: Preliminary results showed that after 1 year BMI z-score was reduced from $2.13(0.32)$ to $1.96(0.43)$ $(\mathrm{p}<0.001)$ among the 96 non-immigrants and from $2.17(0.28)$ to $2.10(0.30)$ $(\mathrm{p}=0.001)$ among the 67 immigrants (between groups $\mathrm{p}=0.001)$. Conclusions: A combined hospital-public health system approach to childhood/adolescent obesity seems to be feasible and was associated with reductions in BMI Zscore. The program seems to be more effective among non-immigrants than among immigrants. A limitation of the study is the lack of an untreated control group.

Conflicts of interest: The authors have no conflicts of interest to declare.

Funding: The study was supported by grants from the Norwegian Foundation for Health and Rehabilitation, The Norwegian Women's Public Health Association, Ullevaal University Hospital Scientific Advisory Committee, the South-Eastern Norway Regional Health Authority, The Norwegian Ministry of health and care services and the Norwegian Directorate of Health.

\section{OP11}

Effect of Regular Exercise in Prevention of Excessive Weight Gain in Pregnancy: A Single Blind Randomized Controlled Trial

Haakstad, L.A.H.; Bø, K.

Norwegian School of Sport Sciences, Oslo, Norway

Excessive weight gain during pregnancy is associated with hypertension, diabetes, pre-eclampsia, macrosomia, delivery complications, stillbirths and postpartum weight retention. Purpose: The aim of the present study was to assess 
whether an aerobic dance exercise program during pregnancy can prevent excessive maternal weight gain Methods: One-hundred and five sedentary, primiparous women, mean age $30.7( \pm 4.0)$ years, were randomized to either an exercise group (EG, $n=52)$ or control group $(\mathrm{CG}, \mathrm{n}=53)$. The exerciseprogram followed the American College of Obstetricians and Gynecologist (ACOG) exercise prescription, and consisted of supervised aerobic dance and strength training for 60 minutes, performed at least 2 times per week for a minimum of 12 weeks. Main outcome measures were maternal weight gain and the proportion of women who exceed the Institute of Medicine (IOM) recommendations. Secondary outcomes were skin-fold thickness and the womens weight postpartum. Differences between the two groups were tested using independent sample and $X^{2}$-tests. The principal analysis was done on an intention to treat basis (ITT). Results: Drop-out rates were $19.2 \%$ and $20.8 \%$ in the EG and CG, respectively. The EG participated in mean $17.0( \pm 12.5)$ out of 24 possible exercise classes. Mean pregnancy weight gain $(\mathrm{kg})$ was 13.0 $( \pm 4.0)$ and $13.8( \pm 3.8)$ in the EG and CG, respectively $(\mathrm{p}=0.31)$. Less women in the EG than the CG exceeded the IOM recommendations, but with a significant difference between EG and CG among women attending all 24 exercise sessions, only $(\mathrm{p}=0.006)$. Women attending 24 exercise sessions $(\mathrm{n}=14$ reduced maternal weight gain compared to women attending less exercis sessions $(11.0 \pm 2.3$ vs. $13.8 \pm 4.3, \mathrm{p}=0.006)$ and compared to the control group $(11.0 \pm 2.3$ vs. $13.8 \pm 3.8, p=0.001)$. Conclusions: Only women attending regularly to the exercise program significantly reduced maternal weight gain. Further studies on adherence strategies to improve compliance are warranted.

Conflict of interest: There are no competing conflicts of interest with regard to his study. Funding: This was a university initiated study and no financial support was given.

OP12

\section{Fat and Carbohydrate Intake Modify the Association between Genetic Variation in FTO and Obesity}

\section{Sonestedt, E. ${ }^{1}{ }^{2}$; Roos, C. ${ }^{2}$; Gullberg, B. ${ }^{1}$; Ericson, U. ${ }^{1}$;}

\section{Wirfält, E. ; Orho-Melander, M. ${ }^{2}$}

${ }^{1}$ Nutrition Epidemiology; and ${ }^{2}$ Diabetes and cardiovascular disease - genetic epidemiology, Department of Clinical Sciences in Malmö Lund University, Sweden

Background: The fat mass and obesity associated gene (FTO) is the stronges common genetic predictor of obesity known so far. The FTO gene is highly expressed in hypothalamus, a region involved in appetite regulation, and the risk-allele has been associated with increased energy intake, especially fat intake and altered appetite. The increased genetic susceptibility of obesity may be modified by environmental factors, particularly physical activity and diet composition. For example, results from several studies suggest that high physical activity may reduce the impact of the FTO A-allele on risk of obes ity. In a similar manner, diets with different macronutrients composition (i.e. fat, carbohydrate and protein) and fibre content could influence appetite and satiety and thereby influence the risk. Objective: The aim was to examine whether dietary factors (macronutrient and fibre intakes) and physical activity modulate the association between genetic variation in FTO and obesity. The availability of detailed data on energy expenditure and dietary data of high validity allow us to exclude individuals with suspected mis-reporting of energy intake. We also have the ability to exclude individuals that reported significant dietary change in the past. Design: A cross-sectional study examined 2,959 women and 2,040 men with dietary data (from a modified diet history method) and direct anthropometric measures collected during the baseline examination in the population-based Malmö Diet and Cancer study. Leisure time physical activity was determined from the duration participants spent on 18 different physical activities. Genetic variant in FTO (rs9939609) was successfully genotyped in 4,839 of the subjects. Results: AA-carriers had increased risk of obesity (OR, 1.71; 95\% CI, 1.26-2.34; P-trend, 0.001 for women; OR, 1.42; 95\% CI, 0.95-2.12; P-trend, 0.09 for men). Among women, we found higher frequency of individuals with suspected underreporting of energy among A-carriers compared to TT-carriers (19-20\% vs. $16 \%, \mathrm{P}=0.02$ ) After excluding potential non-adequate reporters, AA-genotype was positively associated with obesity only in individuals reporting high-fat diet (women: P-trend $=0.005$ and P-inter-action $=0.07$; men: $\mathrm{P}$-trend $=0.02$ and $\mathrm{P}$ interaction $=0.09$ ) or low-carbohydrate diets (women: P-trend $<0.001$ and $\mathrm{P}$ interaction $=0.03$; men: $\mathrm{P}$-trend $=0.01$ and $\mathrm{P}$-interaction $=0.02)$. The increase in $\mathrm{BMI}$ across genotypes was mainly restricted to individuals reporting low leisure-time physical activity (P-trend=0.04 for women and men). Conclusion: Our results indicate that high-fat diets and low physical activity may accentuate the susceptibility for obesity by the FTO variant.

\section{OP13}

\section{Prevalence of MC4R Mutations in Obese Pediatric Patients in}

\section{Norway}

Wangensteen, T. ${ }^{1,2}$; Pollestad Kolsgaard, M.L. ${ }^{3}$; Mattingsdal, M. ${ }^{4}$;

Joner, G. ${ }^{3,5}$; Tonstad, S. ${ }^{6}$; Undlien, D. ${ }^{2,1}$; RetterstøI, L. ${ }^{1}$

${ }^{1}$ Department of Medical Genetics, Oslo University Hospital, Ullevål, Oslo,

Norway

${ }^{2}$ Institute of Medical Genetics, University of Oslo, Oslo, Norway

${ }^{3}$ Department of Pediatrics, Oslo University Hospital, Ullevål, Oslo, Norway

${ }^{4}$ Bioinformatics Core Facility, Oslo University Hospital, Oslo, Norway

${ }^{5}$ Institute of Health Management and Health Economy, University of Oslo, Norway

${ }^{6}$ Department of Preventive Cardiology, Oslo University Hospital, Ullevål,

Oslo, Norway

Purpose: Mutations in the melanocortin 4 receptor $(M C 4 R)$ gene are the most frequent monogenic cause of obesity. Most patients are heterozygous for the mutation, but codominant inheritance is also seen. Reported frequencies vary from $0.2 \%$ up to $5.8 \%$ in obese populations. We assessed the prevalence and nature of $M C 4 R$ mutations in obese children and adolescents referred to the Department of Pediatrics, Ullevaal in Oslo, Norway. Methods: A total of 437 participants from the ongoing 'Oslo Adiposity Intervention Study' (body weight $>97.5$ percentile for height) were screened for mutations in the $M C 4 R$ gene. Novel mutations were analyzed by a bioinformatic approach and family studies. Results: We identified a total of six mutations in this cohort, of which five have been described in a recent publication. The last identified mutation was the novel G55D mutation found in homozygous state in an eight year old girl with consanguineous parents from Pakistan. The proband had a typical $M C 4 R$-phenotype with normal birth weight $(3000 \mathrm{~g})$, but early onset of obesity with body weight crossing the 97.5 weight for height percentile at 4-5 months, and an increased appetite. Parents and three siblings were examined. Phenotype and genotype segregated well within the family. The two homozygous children both had a similar phenotype regarding severity, onset and eating behavior. The phenotype of heterozygous family members varied. Bioinformatic analyses revealed $\mathrm{G}$ (glycine) at position 55 to be $100 \%$ conserved in vertebrates, and the substitution with D (aspartate) to substantially change the property of this residue. Meanwhile Tan et al published a functional evaluation of the same mutation, with the conclusion that it reduces receptor activation. The prevalence of $M C 4 R$ mutations in our cohort was $1.6 \%$. Two out of $6 M C 4 R$ mutations were identified in a homozygous state. M200del was found in a consanguineous family from Turkey, where two obese siblings were homozygous for the mutation and the third slim child was wild type. Both homozygous, and three of the four heterozygous mutations were found in second generation immigrants from non-Scandinavian countries, which make up around $60 \%$ of the children in the cohort. Conclusions: The prevalence of MC4R mutations in obese pediatric patients in Oslo was $1.6 \%$. Five of six identified mutations were found in immigrants.

Conflicts of interest: None.

Funding: The study was supported by grants from the Norwegian Foundation for Health and Rehabilitation, Ullevål University Hospital Scientific Advisory Committee (VIRUUS), University of Oslo and the Eastern Regional Health Authority.

OP14

\section{A 12-Week Exercise Programme Improves Short-Term Appetite Control in Overweight/Obese Volunteers}

\section{Martins, C. ${ }^{1}$; Kulseng, B. ${ }^{1}$; King, N.A. ${ }^{2}$; Blundell, J.E. ${ }^{3}$}

${ }^{1}$ Obesity Research Group, Department of Cancer Research and Molecular Medicine, Faculty of Medicine, Norwegian University of Science and Technology, Trondheim, Norway;

${ }^{2}$ Institute of Health and Biomedical Innovation, Queensland University of Technology, Brisbane, Australia

${ }^{3}$ BioPsychology Group, Institute of Psychological Sciences, University of Leeds, Leeds, United Kingdom

Introduction: Cross-sectional studies have shown a more accurate energy compensation in active versus sedentary normal-weight individuals. Moreover, a 6week exercise programme has been shown to improve short-term appetite regulation over a $24 \mathrm{~h}$ period in normal-weight individuals. This study aims to investigate the effects of a 12-week exercise programme (5 times/week, 75\% maxHR) on appetite regulation in overweight/obese sedentary volunteers. Methods: Pasta lunch energy intake (EI) $60 \mathrm{~min}$ after high-energy (HEP;607kcal) and low-energy (LEP; 246kcal) preloads, and cumulative EI for the rest of the day, were measured in 15 overweight/obese volunteers (age:36.9 \pm 8.3 years, BMI: $31.3 \pm 3.3 \mathrm{~kg} / \mathrm{m}^{2}$ ). Feelings of appetite were assessed throughout using visual analogue scales. Fasting/postprandial insulin, glucose and gut peptides plasma levels were also measured before and after the intervention. Results: ANOVA showed a significant preload*exercise interaction $(\mathrm{P}=0.011)$ on cumulative 
EI and energy compensation over the same period improved significantly ($87 \pm 196$ vs. $68 \pm 165 \%, P=0.011$ ). The same was not reflected acutely at the pasta lunch. ANOVA showed no effects of exercise, preload or interactions on feelings of appetite between preload and lunch. Weight loss was uncorrelated with improvements in energy compensation. A significant improvement in insulin sensitivity was observed. Conclusion: This study suggests that exercise improves appetite regulation, over the course of a day, by leading to a more sensitive eating behaviour in response to previous EI in overweight/obese individuals The improvements observed seem to be independent of weight loss and a direct result of exercise itself. The improved appetite sensitivity may be related to increased insulin sensitivity; however, further mechanistic studies are needed.

Conflict of interest: None Disclosed.

Funding: Catia Martins was supported by a PostDoctoral grant (SFRH/

BPD/36940/2007) from Fundação para a Ciência e Tecnologia (Portugal) under the 3rd

European Union community support programme.

\section{OP15}

\section{Is Abdominal Obesity Associated with Arterial Stiffness and Endothelial Dysfunction in Morbidly Obese Patients?}

Nordstrand, N. ${ }^{1}$; Dinh, K.N. ${ }^{2}$; Saltvedt, E. ${ }^{1}$; Gjevestad, E. ${ }^{3}$;

Fon, H.O. ${ }^{1}$; Hofs $\varnothing$, D. ${ }^{1}$; Sandbu, R. ${ }^{1,4}$; Hjelmesæth, J. ${ }^{1}$

${ }^{1}$ Morbid Obesity Centre, Vestfold Hospital Trust, Tønsberg, Norway

${ }^{2}$ Department of Surgery, Innlandet Hospital Trust, Kongsvinger, Norway

${ }^{3}$ Hospital for Rehabilitation, Department of Physical Medicine, Stavern,

Norway.

${ }^{4}$ Department of Surgery, Vestfold Hospital Trust, Tønsberg, Norway.

Purpose: To investigate the effects of various measures of obesity on arterial stiffness and endothelial function, both generally accepted surrogate mark ers for cardiovascular disease. Methods: Cross-sectional analysis of baseline data from a prospective non-randomized controlled study comparing the effects of a comprehensive lifestyle modification program and bariatric surgery (Prevention of Coronary Heart Disease in Morbidly Obese Patients (SphCor) ClinicalTrials.gov Identifier NCT00626964). Arterial stiffness, endothelial function and anthropometric measures were assessed in 100 consecutive morbidly obese patients ( $59 \%$ women). The Sphygmocor system (Artcor, Sidney, Australia) and a single high-fidelity applanation tonometer (Millar $\left.{ }^{\circledR}\right)$ were used to measure arterial stiffness and endothelial function expressed by pulse wave velocity (PWV) and augmentation index (AIx), respectively. Spearman`s correlation, independent samples T-test and multiple linear regression were used as statistical methods. Results: The patients had a mean (SD) age of 43 (11) years, BMI $43.9(5.5) \mathrm{kg} / \mathrm{m}^{2}$, waist circumference (WC) $131(12) \mathrm{cm}$, waist to hip-ratio (WHR) $1.00(0.10)$, height $(\mathrm{H}) 1.72(0.08) \mathrm{m}$. AIx was negatively correlated with WC $(r=-0.295)$, WHR $(r=-0.256), \mathrm{H}(\mathrm{r}=$ 0.428 ), all p-values $<0.05$, but not with BMI. PWV was positively correlated with WC $(r=0.254)$, WHR $(r=0.408)$, both $p$-values $<0.05$, but not with BMI or H. Women had a significantly higher mean AIx and a significantly lower PWV than men; 24 (9) \% vs. 16 (10) \%, p<0.001, and 9.5 (2) m/s vs. 8.0 (2) $\mathrm{m} / \mathrm{s}, \mathrm{p}=0.001$. Multiple linear regression revealed that increasing age and $\mathrm{fe}$ male gender, but not BMI, WC or WHR, were associated with increasing AIx ( $\mathrm{p}<0.001, \mathrm{p}=0.016, \mathrm{p}=0.633, \mathrm{p}=0.800$, and $\mathrm{p}=0.414$ respectively $)$. Partly contrasting this finding, increasing age and BMI, but not gender, WC or WHR, were associated with increasing PWV $(p<0.001, p=0.039, p=0.359, p=0.207$ and $\mathrm{p}=0.993$ respectively). Conclusion: Overall obesity (BMI), but not abdominal obesity, was associated with arterial stiffness in our study of morbidly obese patients. Neither abdominal, nor overall obesity was associated endothelial dysfunction. We confirm previous findings in less obese populations of a higher mean AIx in women than in men. The scientific background for this finding is not fully understood and needs further investigation.

Conflict of interest: None disclosed.

Funding: Dag Hofs $\varnothing$ has received unrestricted educational grants from Novo Nordisk A/S, South-Eastern Norway Regional Health Authority and Vestfold Hospital Trust.

\section{OP16}

Dietary Changes Associated with Reduction in Diastolic Blood Pressure in 157 Subjects with Overweight/Obesity Randomized to a Low-Fat Diet or a Low Glycemic Load Diet

\section{Klemsdal, T.O. ${ }^{a}$; Holme, I. ${ }^{a}$; Pedersen, T.R. ${ }^{a, b}$; Tonstad, S.}

a Department of Preventive Cardiology, Center for Preventive Medicine, Oslo University Hospital, Ullevål, Kirkeveien 166, N-0407 Oslo, Norway, bUniversity of Oslo, Faculty of Medicine, Oslo Norway

Purpose: Low carbohydrate diets have been demonstrated to lower blood pressure, even on top of established antihypertensive diets (e.g. DASH). The present study examined dietary factors associated with a reduction in diastolic blood pressure in subjects with overweight or obesity, who participated in a randomized trial over 12 months comparing a conventional low-fat diet versus a low glycemic load (LGL) diet. Methods: Men and women aged 30-65 years, with a BMI of $28-40 \mathrm{~kg} / \mathrm{m}^{2}$ (28-35 for women) and at least one criterion of metabolic syndrome were eligible. Complete 7-day dietary records were obtained after 3 months in 157 subjects, of the total study sample of 202 subjects. A multiple regression analysis was performed with the 12 month change in diastolic blood pressure as the dependent variable, and several dietary variables were tested as possible predictors. In addition, the 12 month change in body weight was included in the analysis to adjust for differences in adherence. Results: Diastolic blood pressure was reduced by 4.5, 3.7, 1.4 and $1.0 \mathrm{mmHg}$, respectively, for the lowest through the highest quartile of bread consumption (all types) $(\mathrm{p}<0.05)$ when adjusted for changes in body weight, which was also a significant predictor $(\mathrm{p}<0.05)$. No significant associations were observed between reduction in blood pressure and the total intake of carbohydrates, fat or protein. Conclusion: Reduced bread consumption, but not reduced total carbohydrate intake, was associated with a reduction in diastolic blood pressure after 12 months on randomized diets. Possibly, a reduction in bread eating is associated with reduced sodium intake or other factors related to blood pressure regulation.

\section{OP17}

\section{Effects on Adipokines of Diets Low in Fat or Low in Carbohydrates}

Heggen, E. ${ }^{1}$; Klemsdal, T.O. ${ }^{1}$; Pedersen, T.R. ${ }^{1,2}$;Haugen, F. ${ }^{3}$; Holme, I. ${ }^{1}$; Tonstad, $S$.

${ }^{1}$ Department of Preventive Cardiology, Oslo University Hospital, Ullevål, Oslo, Norway

${ }^{2}$ University of Oslo, Faculty of Medicine, Oslo, Norway

${ }^{3}$ Department of Nutrition, Institute of Basic Medical Sciences, University of Oslo, Oslo, Norway

Purpose: We compared effects of two mildly hypocaloric diets (i.e. $-500 \mathrm{kcal} /$ day), a low-fat diet ( $<30 \%$ fat, about $15 \%$ protein, $55-60 \%$ carbohydrate) and a low carbohydrate diet (35-40\% fat, $25-30 \%$ protein, $30-35 \%$ carbohydrate) on plasma concentrations of different adipokines including leptin, adiponectin, resistin, plasminogen activator inhibitor-1 (PAI-1), interleukin-6 (IL-6), tumor necrosis factor $\alpha(\mathrm{TNF} \alpha)$ and monocyte chemo-atractant protein-1 (MCP-1). Methods: 202 men and women aged 30-65 years, with a BMI of $28-40 \mathrm{~kg} / \mathrm{m}^{2}$ (28-35 for women) and one or more criteria of the metabolic syndrome as defined by the National Cholesterol Education Program were randomized to 1 of the two diets. Plasma samples were taken at baseline and at 3 months and analyzed in duplicates using multiplexed microsphere immunoassays and a Bio-Plex ${ }^{\mathrm{TM}} 200$ instrument. Results: Weight loss was not significantly different in the low carbohydrate $(-4.9 \pm 3.4 \mathrm{~kg})$ compared to the low-fat group $(-4.3 \pm 4.0 \mathrm{~kg})$. Both diets reduced leptin concentrations, but there was no significant change in adiponectin or resistin in any of the diet groups. There was a significant reduction in concentrations of PAI-1, IL-6 and TNF $\alpha(P<0.001)$ and in MCP-1 $(P=0.047)$ in both groups.

\begin{tabular}{|l|l|l|l|l|l|l|}
\hline Adipokine & $\begin{array}{l}\text { Baseline } \\
\text { mean } \pm \text { SD } \\
\mathrm{N}=181\end{array}$ & $\begin{array}{l}\text { At 3 months } \\
\text { mean } \pm \text { SD } \\
\mathrm{N}=181\end{array}$ & $\mathrm{P}$ & $\begin{array}{l}\text { Low carbo- } \\
\text { hydrate group } \\
\% \text { change } \\
\mathrm{N}=93\end{array}$ & $\begin{array}{l}\text { Low-fat } \\
\text { group } \\
\% \text { change } \\
\mathrm{N}=88\end{array}$ & $\begin{array}{l}P \\
\text { between } \\
\text { diets }\end{array}$ \\
\hline $\begin{array}{l}\text { Leptin } \\
\mathrm{ng} / \mathrm{ml}\end{array}$ & $\begin{array}{c}27.91 \pm \\
16.28\end{array}$ & $\begin{array}{c}22.27 \pm \\
14.87\end{array}$ & $<0.001$ & 13.9 & 12.0 & 0.74 \\
\hline $\begin{array}{l}\text { Adiponectin } \\
\mu \mathrm{g} / \mathrm{ml}\end{array}$ & $\begin{array}{c}18.22 \pm \\
10.40\end{array}$ & $\begin{array}{c}18.09 \pm \\
10.00\end{array}$ & 0.712 & 5.9 & 0.1 & 0.16 \\
\hline $\begin{array}{l}\text { Resistin } \\
\mathrm{ng} / \mathrm{ml}\end{array}$ & $\begin{array}{c}15.25 \pm \\
7.37\end{array}$ & $\begin{array}{c}14.60 \pm \\
6.66\end{array}$ & 0.161 & -4.2 & 3.5 & 0.07 \\
\hline $\begin{array}{l}\mathrm{PAI}-1 \\
\mathrm{ng} / \mathrm{ml}\end{array}$ & $\begin{array}{c}42.38 \pm \\
12.24\end{array}$ & $\begin{array}{c}38.15 \pm \\
9.99\end{array}$ & $<0.001$ & 8.7 & 37.1 & 0.47 \\
\hline $\begin{array}{l}\mathrm{IL}-6 \\
\mathrm{pg} / \mathrm{ml}\end{array}$ & $\begin{array}{c}10.60 \pm \\
12.83\end{array}$ & $\begin{array}{c}9.13 \pm \\
10.33\end{array}$ & $<0.001$ & 3.2 & 11.7 & 0.42 \\
\hline $\begin{array}{l}\mathrm{MCP}-1 \\
\mathrm{pg} / \mathrm{ml}\end{array}$ & $\begin{array}{c}314.62 \pm \\
139.16\end{array}$ & $\begin{array}{c}303.60 \pm \\
121.85\end{array}$ & 0.047 & 1.4 & 1.3 & 0.57 \\
\hline $\begin{array}{l}\mathrm{TNF} \alpha \\
\mathrm{pg} / \mathrm{ml}\end{array}$ & $\begin{array}{c}7.62 \pm \\
5.53\end{array}$ & $\begin{array}{c}6.86 \pm \\
4.45\end{array}$ & $<0.001$ & 6.4 & 6.6 & 0.72 \\
\hline
\end{tabular}

Conclusion: Both the diets, low carbohydrate and low-fat, improved concentrations of leptin, PAI-1, IL-6, TNF $\alpha$ and MCP-1, but there were no differences between the diets. 
OP18

3-Dimensional (3-D) Laser Body Scanner for Measurement of Waist and Hip Circumferences and Body Volume

Freeland-Graves, J.H.; Pepper, M.R.; Lee, J.; Maximo, I.;

Zhu, Y.; Xu, B.

University of Texas at Austin, Texas, United States of America

Purpose: The purpose was to evaluate the reliability and validity of a 3-D laser body scanner to assess waist and hip circumferences and body volume. Methods: Reliability was tested by eight repeated measurements of body imaging performed on 70 women. Validity was assessed by comparisons of measures from 3-D body imaging to that obtained by tape for circumferences and by hydrodensitometry (HD) for body volume. Results: Reproducibility analysis showed minimal differences between within-subjects measurements of circumference or volume (ICC $\geq 0.99, \mathrm{p}<0.01)$. Abdominal and hip circumferences via body scanning did not differ significantly from tape measure $(\mathrm{p}>0.05)$. Body volume estimations by laser body scanner and HD were strongly related $(\mathrm{r}=0.99, \mathrm{p}<0.01)$, with high agreement $(\mathrm{ICC}=0.99, \mathrm{p}<0.01)$ Bland-Altman analysis showed minimal bias between laser scanning and criterion methods. Conclusions: 3-D laser body scanning is a reliable and valid technique for estimation of waist and hip circumference. Also, it provides an accurate measure of body volume as compared to HD. This instrument is promising as a technique in the assessment of obesity.

Conflicts of interest: None.

Funding: The funding is from National Institutes of Health \# 1 R21 K081206-01 (United States of America).

OP19

Conceptions of Obesity and Obesity Treatment among Primary Health Care Specialists

Hansson, L.M. ${ }^{1}$; Ahlström, G. ${ }^{2}$

${ }^{1}$ Karolinska Institutet, Stockholm, Sweden

${ }^{2}$ School of Health Sciences, Jönköping University, Sweden

Purpose: Primary health care specialists have a key role in the management of obesity. By understanding how they relate to their patients and their knowledge about the causes and consequences of obesity the treatment may be improved. Few qualitative studies have been conducted in this area of research and therefore the aim of this study was to explore general practitioners' (GPs) and district nurses' (DNs) conceptions of obesity and obesity treatment. Methods: Data were collected (between April 2008 and March 2009) through interviews and analysed in accordance with a phenomeno-graphical approach. Participants included $10 \mathrm{GPs}$ (4 men) and 10 DNs (3 men) between the ages 34 and 60 at 19 different primary health care centres in Stockholm County Council. Their length of professional experiences varied between 1-32 years. Results: Preliminary findings reveal that the causes of obesity were conceived in four different ways that is: unhealthy lifestyle, inability to resist eating, interplay of genes and lifestyle, and structural patterns in society. The categories are interrelated but have different focus, namely the individual and the society. Most participants had more than one view, but few included all four. Treatment of patients with obesity was described in terms of identifying facilitators and barriers for the patient. Emerging conceptions of obesity treatment within primary health care among GPs and DNs are presented at the conference. Conclusion: Understanding primary health care specialist's conceptions of obesity and obesity treatment encounters is important to improve practice.

Funding: Research relating to this abstract was funded by Swedish Health Care Sciences Postgraduate School, Karolinska Institutet, Stockholm.

\section{OP20}

\section{Can Personality Traits Affect the Motivation for Lifestyle}

\section{Changes?}

Gade, H.; Hjelmesæth, J.

Morbid Obesity Centre, Vestfold Hospital Trust, Tønsberg, Norway

Purpose: We aimed to assess whether personality traits are associated with motivation (autonomous vs. controlled self-regulation) for lifestyle changes in overweight and obese subjects. Methods: A total of 187 overweight $(n=57)$ or obese $(n=130)$ subjects who participated in a commercial weight management program (mean age $44, \mathrm{SD}=13$ ) completed three different Self-determination (SDT)-questionnaires: The Treatment Self-regulation questionnaire (TSRQ, diet and exercise), the Health Care Climate Questionnaire (HCCQ diet and exercise) and the General Causality Orientation Scale (GCOS). Personality traits were assessed by the NEO Five-Factor Inventory (NEO-FFI).
Pearson's correlations and multiple linear regressions were used to assess the associations between personality variables (independents) and self-regulation (dependent). We performed four separate multiple linear regression analyses by including controlled self-regulation (diet and exercise), and autonomous self-regulation (diet and exercise) as dependent variables (Model 1-4), and personality traits, age, BMI and autonomy support as independent variables in all models. Results: We found statistically significant $(\mathrm{p}<0.01)$ correlations between the following personality traits and self-regulation: Neuroticism (N) and controlled self-regulation ( $r=.48$ for diet and $r=.40$ for exercise), conscientiousness (C) and autonomous self-regulation ( $\mathrm{r}=.23$ for diet and $\mathrm{r}=.25$ for exercise), extroversion and autonomous self-regulation ( $\mathrm{r}=.16$ for diet and $\mathrm{r}=.23$ for exercise). We also found a significant correlation between BMI and controlled self-regulation (exercise) ( $\mathrm{r}=.24)$. Model 1 and 2 explained 21 and $24 \%$ of the variation in controlled self-regulation (exercise and diet, r-square $=0.21$ and 0.24 respectively). Among the personality traits, neuroticism explained most of the variation in controlled self-regulation, both for exercise and diet $(\mathrm{p}<0.05)$. Finally, model 3 and 4 explained 5 and $7 \%$ of the variation in autonomous self-regulation (exercise and diet), $\mathrm{r}$-square $=0.05$ and 0.07 respectively. Conclusion: Our results indicate that personality traits may affect the type of self-regulation for overweight and obese, and that personality traits may influence the motivation for lifestyle changes. Assessing patients' personality traits may help health care providers to identify patients who probably will have more difficulties to adhere and therefore may need more follow-up to improve medical or behavioral adherence.

Conflicts of interest: The authors declare no conflicts of interest.

OP21

Body Size Perceptions among Pakistani Women in Norway with a High Risk of Diabetes

Hussain, A. ${ }^{1}$; Bjørge, B. ${ }^{1}$; Hjellset, V.T. ${ }^{2}$; Holmboe-Ottesen, G. ${ }^{2}$; Wandel, $M$.

${ }^{1}$ Department of Nutrition, Institute of Basic Medical Sciences, University of Oslo, Pb 1046 Blindern, 0316 Oslo, Norway

${ }^{2}$ Section for Preventive Medicine and Epidemiology, Institute of General Practice and Community Medicine, University of Oslo, Pb 1130 Blindern, 0318 Oslo, Norway

Purpose: South Asians are prone to diabetes type 2 and cardiovascular diseases, which can be prevented by a diet leading to weight reduction. Body size perceptions may influence compliance to dietary advice. The objective was to study body size perceptions among immigrant Pakistani women participating in an intervention project focussed on diet and physical activity. Method: 198 women aged 26 to 65 years, born in Pakistan, residing in Norway (79.8\% had BMI $>25$, mean BMI 29.6). Data collection by questionnaire interviews with Punjabi/Urdu speaking interviewers. Stunkard's figure rating scale was used. This consists of 9 figures, representing women with different body shapes, from very thin (1-2) to very obese (6-9). Body weight and height were measured by project personnel. This article is based on data from baseline. Results: The women were asked which body size they meant would connote health and wealth. A significantly smaller body size was related to health (mean 2.9) than to wealth (mean 3.3), p<0.01, and both were smaller than their self rated own body size (5.7), $\mathrm{p}<0.01$. The women perceived that Pakistanis in Norway prefer women to have a smaller body size (mean 3.4) than people in Pakistan (mean 4.5), but larger than Norwegians (mean 2.5). A discrepancy score was calculated between self rated own body size and the body size they meant that Pakistanis in Norway prefer. BMI was positively associated, and level of education negatively associated with the discrepancy score. The Pakistani women related body size numbers to BMI similarly to what has been described for Caucasian women. Conclusion: Body size preferences among the Pakistani women in Norway are within the range of normal weight. There is a large discrepancy between own self rated body size and what the women perceive to be the ideal for Pakistanis in Norway.

\section{OP22}

\section{An Interview- Question-Based Approach Improves Behavioral} Change and Weightloss in the Treatment of Obesity

Larsen, M.A. *; Lekhal, S. *; Birketvedt, G.S. **; Florholmen, J.* Laboratory of Gastroenterology and Nutrition, University of Troms $\varnothing^{*}$, Department of Surgery, Aker University Hospital**, Oslo; Norway

Background; Life style changes are the best way to obtain long term health benefits in overweight and obese patients. Several programs of behavioral change in lifestyle have been used. However, their efficacy to promote long term behavioral results and improvements in metabolic markers are not well 
documented. Aim: Develop a behavioral score for weight loss by evaluating changes in lifestyle using interview- question based method in the treatment of overweight and obesity. Material and Methods: 14 obese (BMI>30) females and males without any metabolic disorders volunteered to participate in the interview- question-based method to lose weight. To evaluate the behavioral changes we used an interview questionnaire with 5 different grades for each question (weight loss behavior scale WLBS), developed with guidance from Multisystemical treatment (MST). The participants were interviewed with the questionnaire before, during and after the first 12 month treatment period. The treatment was individual and no specific diet regimen were given (Mean =12,6 consultations). Clinical (blood pressure, total body weight, waist circumference, hip circumference; dual- X-Ray-absorptiometry (DEXA), total fat weight, total fat $\%$, abdominal fat $\%$, gynoid fat $\%$, total muscle mass and android/gynoid ratio (A/G-ratio)) and metabolic markers, (plasma total cholesterol, LDL, HDL, triglycerides, fasting blood glucose) were measured at baseline and after 12 months. Results: 3 out of the 14 subjects were withdrawn due to practical or psychosocial events. The remaining 11 patients fulfilled the study according to the protocol. In this group there were significant reductions in WLBS score from baseline to 6 months $(-20$ points (95\% CI: $1,96,38,0 . \mathrm{p}<0,037)$ and to 12 months $(-25,4$ points $(95 \% \mathrm{CI}$ : $9,1,41,6 . p<0,012)$. Improvements were also observed for the various clinical and metabolic parameters. Conclusion: An interview- question-based approach improves behavioral change and improves clinical and metabolic profiles after 12 months in obese subjects. This specific intervention behavioral change program may be useful for long term treatments.

Conflicts of interest: None.

Funding: Medical faculty, University of Troms $\varnothing$, Norway.

\section{OP23}

\section{Morbidly Obese Patients - Who Undergoes Bariatric Surgery?}

Jakobsen, G.S.; Hofs $\varnothing$, D.; Røislien, J.; Sandbu, R.; Hjelmesæth, J.

Morbid Obesity Center, Vestfold Hospital Trust, Tønsberg, Norway

Introduction: We aimed to examine whether morbidly obese patients referred to bariatric surgery are characterized by a higher prevalence of major obesity related comorbidities such as type 2 diabetes (T2DM), hypertension and ob structive sleep apnea (OSA), than those offered conservative therapy. Methods: A total of 511 consecutive morbidly obese patients, $72 \%$ women, with mean (SD) age of 42 (12) years, attended our tertiary care centre between December 2005 and February 2007. All patients were examined by a multidisciplinary team and offered conservative or surgical treatment. Chi-square test, independent sample t-test and multiple logistic regression were used for statistics. Results: A total of 249 (49\%) patients underwent bariatric surgery. The surgery group was characterized by a significantly higher mean (SD) BMI (46.5(6.2) vs. $\left.43.2(5.5) \mathrm{kg} / \mathrm{m}^{2}, \mathrm{p}<0.001\right)$, earlier debut of obesity (40\% vs $26 \%$ before 12 years of age, $\mathrm{p}<0.001)$ and a lower age (41(11) vs. 44(13) years, p 0.002), as compared with the conservative group. In contrast, the groups did not differ significantly with respect to gender or obesity related comorbidities. Multiple regression revealed that patients with BMI between 40 and 50 or above $50 \mathrm{~kg} / \mathrm{m}^{2}$ had a 3- to 6 -fold increased odds for undergoing bariatric surgery as compared to patients with a BMI $<40 \mathrm{~kg} / \mathrm{m}^{2}$ (reference), even after adjustment for gender, age, debut of obesity and comorbidities. Conclusion: Our results indicate that increasing BMI, earlier debut of obesity and lower age, but not obesity related comorbidities, predicted treatment choice in morbidly obese patients.

Conflicts of interest: The authors declare no conflicts of interest.

\section{OP24}

\section{The Type of Obesity Treatment Affects Drop-Out Frequency}

Karlsson, T.1, ${ }^{2}$; Larsson, I. ${ }^{2}$; Lantz, H. $^{2}$; Stenlöf, K. ${ }^{2,3}$

${ }^{1}$ Department of Physiology/Endocrinology, Institute of Neuroscience and Physiology, The Sahlgrenska Academy at University of Gothenburg, Sweden, ${ }^{2}$ Obesity unit, Sahlgrenska University Hospital, Gothenburg, ${ }^{3}$ Department of Clinical trials and Entrepreneurship, The Sahlgrenska Academy at University of Gothenburg

Purpose: Drop-out from obesity treatment is a major problem and can lead to a sub-optimal treatment for the patient and the effect of the available treatment is lost. When drop-out frequency is large the conclusions from studying the effect of treatment can be questioned. The purpose of this analysis is to examine if the type of treatment affects the number of drop-outs

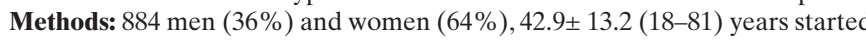
their treatment during 2005 and 2006 at the Obesity unit, Sahlgrenska Uni- versity hospital, Gothenburg. Body mass index at the beginning of treatment was $41.3 \pm 6.6(27.3-76.2) \mathrm{kg} / \mathrm{m}^{2}$. At baseline $20 \%$ of the patients had type 2 diabetes mellitus, $31 \%$ had hypertension and five percent had medically treated dyslipidemia. Results: $46 \%$ of the patients received dietary treatment alone (non-LCD group) while $37 \%$ started their dietary treatment with a 12 week long Low Calorie Diet (LCD), (>500 $\leq 800 \mathrm{kcal} /$ day) period (LCD group). After 6 and 12 months respectively, $31 \%$ and $50 \%$ of all patients had dropped out from treatment. At 6 month the drop-out was $17 \%$ in the LCDgroup compared to $36 \%$ in the non-LCD group and at 12 months the dropout in the LCD-group was $33 \%$ compared to $55 \%$ in the non-LCD group. Weight loss at 6 months was $-16.1 \pm 9.9 \mathrm{~kg}$ and $-3.9 \pm 6.6 \mathrm{~kg}$ in the LCD-group and non-LCD group respectively ( $\mathrm{p}<0.001$ difference between groups). At 12 months weight loss was $-13.2 \pm 11.6 \mathrm{~kg}$ in the LCD group and $-7.1 \pm 9.7 \mathrm{~kg}$ in the non-LCD group ( $\mathrm{p}<0.001$ difference between groups). Conclusions: The results indicates that if the obese patient experience a large weight loss in the beginning of the treatment she is more likely to stay in treatment until 12 months compared to the patients with a smaller initial weight loss.

\section{OP25}

\section{Two Year Lifestyle Change Intervention: Effects on Weight,} Physical Capacity and Perceived Mental Health

Fismen, E.; Lien, A.G.; Robertson, L.

Red Cross Haugland Rehabilitation Center, Flekke, Norway

Purpose: Haugland rehabilitation centre, situated in western Norway, introduced a lifestyle change program for morbidly obese patients in 2006. The program incorporates healthy eating, exercise and education in cognitive behaviour therapy (CBT) - the latter focussing on changing unhelpful/unhealthy thoughts and behaviours that may detrimentally affect change endeavours. To date, 10 groups of patients have begun the program which includes residency at the centre five times over two years (for 6 weeks, 4 weeks, and three 2 -week periods). In this study, we document changes in physical and mental health in patients from the first five groups who have completed the program. In addition we describe challenges faced and resultant program adjustments. Methods: Forty-six patients (27 women and 15 men, mean age 41 years) were assessed with respect to changes in weight, Body Mass Index (BMI), aerobic capacity (Sub maximal bicycle test, Åstrand-Rhymings method), depression (Beck's Depression Inventory- BDI) and anxiety (Beck 's Anxiety Inventory- BAI). Results: Mean weight reduction was $10,7 \%( \pm 1$, 1) of initial weight. BMI reduced from $44.6 \mathrm{~kg} / \mathrm{m}^{2}( \pm 1.2)$ to $39.7 \mathrm{~kg} / \mathrm{m}^{2}( \pm 1.1)$, $\mathrm{p}<0,001$. Maximum oxygen uptake increased from $51,2 \%( \pm 10,9)$ to $70,1 \%$ $( \pm 15,5) \mathrm{p}<0,0001$ of predicted value, an increase of $36,8 \%$. Mean BDI reduced from $10,6( \pm 6,3)$ to $5,1( \pm 5,5) \mathrm{p}<0,0001$, a shift from mild to normal range. Mean BAI was reduced from $10,7( \pm 7)$ to $5,9( \pm 5,4) \mathrm{p}<0,0001$, a significant decrease within the normal range. Conclusions: Overall weight loss, increase in physical capacity and improvement in perceived mental health (as indicated by BDI and BAI scores) were significant and likely to produce health gains. Given that (a) only 51 percent (46 of 90) of the initial patient group completed the two year program, (b) participant feedback expressed a desire for more CBT and (c) the most common reasons for abandoning the lifestyle change program (i.e., mental health problems, home/job situation, conflict in the group) can be addressed by CBT, a more structured and practical program for $\mathrm{CBT}$ has been initiated. In addition, criteria for inclusion in the program have been tightened, group size decreased and a plan for increasing flexibility of residential periods initiated. The outcome of these measures, intended to increase the effectiveness of the program, are the subject of ongoing research.

Conflicts of interest: None.

Funding: Funding for the lifestyle change program is provided by the health authority in western Norway. The research presented has been initiated and funded by Haugland Rehabilitation center, the institution where the program takes place.

\section{OP26}

\section{Lifestyle Intervention in Morbidly Obese Patients, Primary or} Tertiary Health Care?

Gjevestad, E. ${ }^{1}$; Smedstad, L.M. ${ }^{1}$; Mæhlum, S. ${ }^{2}$; Olsen, K. ${ }^{3}$; Hjelmesæth, J. ${ }^{4}$

${ }^{1}$ Hospital for Rehabilitation, Department of physical medicine, Stavern, Norway; ${ }^{2}$ Hjelp24, NIMI, Oslo, Norway; ${ }^{3}$ Fritzøe clinic, Larvik, Norway ${ }^{4}$ Morbid Obesity Centre, Vestfold Hospital Trust, Tønsberg, Norway espen.gjevestad@rehabilitering.net

Purpose: We aimed to compare the effects of intensive lifestyle intervention (ILI) in a tertiary care centre and usual care (UC) in general practice, on 
various anthropometric measures in morbidly obese patients. Methods: The ILI-group ( $\mathrm{n}=147,65 \%$ women) received cognitive-behavioural treatment and two sessions of adapted physical activity in groups for three days pr week for twelve weeks. The UC-group ( $\mathrm{n}=24,42 \%$ women) received one individual cognitive-behavioural treatment session and additional support by their general practitioner for twelve weeks. Statistical methods: Paired and independent samples t-tests. Results: A total of 152 patients completed the 12 -weeks program, 139 in the ILI-group and 13 in the UC-group, respectively. The ILIgroup had a significant reduction in mean (SD) weight of 10.0 (13.6) kg, BMI $3.23(3.6) \mathrm{kg} / \mathrm{m}^{2}$, waist circumference (WC) 9.9 (9.6) $\mathrm{cm}$, hip circumference (HC) 6.0 (5.4) cm and neck circumference 2.7 (5.3) $\mathrm{cm}($ all $\mathrm{p}<0.001)$. The UC-group had a significant reduction in mean (SD) weight of 6.7 (4.9) kg $(\mathrm{p}<0.001)$, BMI $2.5(1.8) \mathrm{kg} / \mathrm{m}^{2}(\mathrm{p}<0.001)$, WC $6.6(5.4) \mathrm{cm}(\mathrm{p}=0.001)$, HC 4.4 $(3.7) \mathrm{cm}(\mathrm{p}=0.001)$ and NC $1.1(1.1) \mathrm{cm}(\mathrm{p}=0.004)$. The ILI-group had a sig nificantly larger decline in weight $(\mathrm{p}=0.035), \mathrm{WC}(\mathrm{p}=0.021)$ and $\mathrm{NC}(\mathrm{p}<0.001)$ as compared with the UC-group, but the changes in BMI and $\mathrm{HC}$ did not differ significantly. Conclusion: The ILI-group had a larger average decline in weight, WC and NC than the UC-group, but the changes between BM and $\mathrm{HC}$ did not differ significantly between groups. Our preliminary result should be interpreted with care due to the relatively low number of patients and high attrition rate in the UC-group.

Conflict of interest: None Disclosed.

Funding: Espen Gjevestad has received unrestricted educational grants from the Hospital for Rehabilitation.

\section{OP27}

Reduced Energy Intake Was the Main Contributing Factor to Weight Loss Maintenance as Measured 3 Years after Gastric Bypass Operation

\section{Kjelstrup, L.S. ${ }^{1,2}$; Andersen, J.R. ${ }^{2}$; Strømmen, M. ${ }^{3}$;}

\section{Kulseng, B.E. ${ }^{3} ;$ Mostad, I.L.}

${ }^{1}$ Department of Clinical Service, Division of Clinical Nutrition, St. Olav University Hospital, Trondheim, Norway

${ }^{2}$ Department of Human Nutrition, Faculty of Life Sciences, University of Copenhagen, Denmark

${ }^{3}$ Centre for Obesity, Department of Surgery, St. Olav University Hospital, Norway

Purpose: To evaluate factors contributing to weight loss and weight maintenance in subjects with morbid obesity 3 y after gastric bypass operation $(n=17)$ compared with lifestyle intervention $(n=20)$ in a case-control study design. Methods: Body composition (DXA scanning) was measured baseline and after 3 y intervention. Prospective food intake ( $7 \mathrm{~d}$ pre coded food diary), energy expenditure (indirect calorimetry) and physical activity (7 d recall questionnaire) were measured after 3 y intervention. Fat uptake $\left({ }^{13} \mathrm{C}\right.$ triolein breath test) addressed in operated was compared with pre operated subjects $(n=14)$. Results are presented as medians (range). Results: Weight, lean body mass and fat mass did not differ between groups at baseline. After 3 y intervention weight loss was $32 \mathrm{~kg}(-76$ to -14$)$ in the operated compared with $5 \mathrm{~kg}(-23$ to +9$)$ in the lifestyle group, $p<0.001$ for the change difference. Fat mass decreased in both groups -24 ( -62 to -9.5$) \mathrm{kg}$ vs. -6 ( -19 to $+0.08) \mathrm{kg}), p<0.001$. Lean body mass decreased in the operated group -8 $(-23$ to -0.3$) \mathrm{kg})$ but increased in the lifestyle group $+2(-7$ to +14$) \mathrm{kg})$ $p<0.001$. Energy intake was 1608 (1135 to 2555$) \mathrm{kcal} / \mathrm{d}$ in the operated compared with 2219 (1488 to 3747 ) kcal in the lifestyle group, $p<0.001$. When related to body weight, there was a weak trend of lower energy intake in the operated $(15.7 \mathrm{kcal} / \mathrm{kg})$ compared with the lifestyle group $(17.5 \mathrm{kcal} / \mathrm{kg})$, $p=0.090$. Energy \% from fat, carbohydrate and protein did not differ between groups. Resting energy expenditure was lower in the operated compared with the lifestyle group, 1635 (1500 to 2030$) \mathrm{kcal} / \mathrm{d}$ vs. 1930 (1450 to 2750$) \mathrm{kcal} / \mathrm{d}$ $p=0.005$, thus not when related to body weight; 17.3 (14.5 to 19.9 ) $\mathrm{kcal} / \mathrm{kg}$ vs. 15.4 (12.4 to 23.9$) \mathrm{kcal} / \mathrm{kg}, p=0.135$. Physical activity did not differ between groups. The ${ }^{13} \mathrm{CO} 2$ peak expiration was $0.000359(0.000244$ to 0.000518$)$ $\mathrm{mmol} / \mathrm{min}$ in the operated compared with 0.000347 (0.000153 to 0.000466$)$ $\mathrm{mmol} / \mathrm{min}$ in the pre operated group ( $p=0.905)$, indicating gastric bypass operation did not affect the fat uptake. Conclusions: Gastric bypass operation effectuated a remarkable weight loss compared with lifestyle intervention, as maintained 3 y post intervention. A lower energy intake seemed to be the main contributor to the weight loss. Fat, carbohydrate and protein were similarly distributed in the diets.

Funding: Project materials and methods used for data collection in the study research, is primary financed by research funds at St. Olav University Hospital and from project funds at Copenhagen University, Department of Human Nutrition in Denmark.
OP28

\section{Effect of a Commercial Weight Loss Programme on Cardiovascular Risk Factors}

Tangen, K.; RetterstøI, K.; Holven, K.; Strøm, E.C.; Ottestad, I.

The University in Oslo, Norway

Purpose: The use of commercial weight loss programmes is increasing, and the purpose of this study was to evaluate the short- and long term effect of a much used weight loss programme in Norway on cardiovascular risk factors. Methods: The study consisted of two parts. The first part was prospective, where 38 patients from a lipid clinic completed a weight loss programme (Grete Roede) with duration of eight weeks. The patients were followed for one year with measurements of different biochemical parameters. The second part was observational, where the patients in part one was asked to participate in a clinical follow-up study and to respond to questionnaires. Results The participants achieved significant weight loss $(4,5 \mathrm{~kg}, \mathrm{p}<0.01,95 \%$ CI for mean $[3,0-5,9] \mathrm{kg}$ ) short time after completing the weight loss programme, and a reduced weight was sustained until two years after the end of the programme $(2,7 \mathrm{~kg}, \mathrm{p}<0,01,95 \% \mathrm{CI}$ for mean $[1,0-4,5] \mathrm{kg})$. The participants also reduced their levels of total cholesterol $(-0,54 \mathrm{mmol} / \mathrm{l}, \mathrm{p}<0,05)$, LDL cholesterol $(-0,39 \mathrm{mmol} / \mathrm{l}, \mathrm{p}<0,05)$, triglycerides $(-0,81 \mathrm{mmol} / \mathrm{l}, \mathrm{p}<0,01)$, micro C Reactive Protein $(-2,63 \mathrm{mg} / \mathrm{L}, \mathrm{p}<0,05)$, apolipoprotein B $(-0,10 \mathrm{~g} / \mathrm{l}, \mathrm{p}<0,05)$ and glycohemoglobin A1c $(-0,11 \%, \mathrm{p}<0,05)$ after completing the programme. Most of the biochemical parameters showed no significant change from baseline values in the long term. An estimate of cardiovascular risk using the Framingham risk score among the female participants, showed a sustained reduced risk for cardiovascular disease until 3 years after completing the programme (from 33 to $50 \%$ risk reduction). The questionnaire showed that the participants struggled with maintaining the principles about right food for weight reduction after the end of the programme, this coincides with the observed gradual weight gain. Conclusions: Although the weight loss was not maintained in the long term and biochemical parameters only changed in the short term, cardiovascular risk was considerable reduced after completing the weight loss programme. The reduced risk was also evident in the long term. This indicates a favourable effect of this commercial weight loss programme on the risk for cardiovascular diseases. Clinicians should motivate overweight patients to a moderate weight loss, because small lifestyle changes can have a favourable long term effect on an individual's total risk profile, and thereby possibly slow down the development of cardiovascular diseases.

Conflicts of interest: None.

Funding: Internal local funding.

\section{OP29}

\section{Guidance in Diet and Physical Activity for Prevention of Weight} Gain after Gastric Bypass Surgery

Hanvold, S.; Bø, R.L.; Aas, A.M.; Refsum, H. Department of Clinical Nutrition, Aker University Hospital, Norway

Purpose: Aker University Hospital started with bariatric surgery in 2004. Expected weight loss after bariatric surgery is $60-80 \%$ of the overweight. In time some patients start regaining weight. Available results suggest that among the patients who regain weight, the mean increase is $8,8 \mathrm{~kg} 5 \mathrm{yrs}$ after surgery. In order to prevent this weight gain it may be useful to provide additional follow-ups at the time when the patients start gaining weight. We also want to identify who regains weight and why. Methods: Patients who underwent gastric bypass surgery between January 2006 and June 2008 will be offered to participate. Participants are randomised into two groups: Group A will receive extra guidance and follow-up, while Group B will continue with the existing scheme. Participants in Group A will over the next 2 yrs take part in frequent meetings that focus on nutrition, physical activity, motivation, self-image and self-confidence. To assess dietary habits and physical activity patterns food diaries and physical activity questionnaires are used. Anthropometric and blood pressure measurements will be taken and blood samples will be collected at regular time intervals before and during the study. Primary Outcomes: 1 . To study cross-sectional associations between diet, physical activity and weight in subjects 2 yrs after surgery. 2 . To study if subjects receiving extra guidance in diet and physical activity for 2 yrs experience less weight gain compared to a control group. Secondary Outcomes: 3 . To study cross-sectional associations between diet, physical activity and biomarkers related to obesity and diabetes 2 yrs after surgery. 4 . To study if subjects receiving extra guidance in diet and physical activity for 2 yrs experience other health effects compared to a control group. 5. To validate the new guidance strategy by recording food intake, total energy expenditure and physical activity before and after intervention in both groups. Preliminary Results: 53 
participants were randomised in autumn 2008. The preliminary results after 4 months show no significant changes in body weight, but we found a tendency to weight regain in the control group. The intervention group maintain thei weight loss, while the control group had a weight regain of $1.9 \mathrm{~kg}(\mathrm{p}=0.074)$. The participants will continue follow-up for a period of $2 \mathrm{yrs}$. The results wil be used to validate the effect of extra guidance, and to decide if this treatment shall be offered to all of our patients.

Conflicts of interest: None.

Funding: Aker University Hospital Research Centre has provided funds to the research project; Johnson \& Johnson have donated pedometers to the participants.

\section{OP30}

Bothering Defecation, Mental Well-Being and Social Functioning after Duodenal Switch

Andersen, J.R. ${ }^{1}$; Våge, V. ${ }^{2}$; Aasprang, A. ${ }^{1}$; Natvig, G.K. ${ }^{3}$

${ }^{1}$ Faculty of Health Studies, Sogn and Fjordane University College. Førde,

Norway.

${ }^{2}$ Department of Surgery, Førde Central Hospital. Førde, Norway.

${ }^{3}$ Section of Nursing Science, Department of Public Health and Primary

Health Care, University of Bergen. Bergen, Norway.

Purpose: Defecation characterized by flatulence, diarea and foul-smelling faeces is common after duodenal switch (DS). Previous research has indicated that even if such symptoms often are well tolerated, they may in some cases affect the self-esteem. We therefore questioned if general mental wellbeing and social functioning also could be affected. The aim of this study was therefore to describe the prevalence of bothering defecation (BD), and to study if it was associated with less improvement in mental well-being and social functioning after DS. Methods: Fifty-one patients participated in a prospective cohort study. Mean age was 37.7 years (SD, 8.0), and 54.9\% were women. The outcome variables; mental well-being and social functioning were assessed using the 'Short-Form 36' (SF-36). BD was assessed by selfreport according to a standardized questionnaire, and was defined as present or not present. Multiple linear regression analysis was used to study associations between $\mathrm{BD}$ and changes in the outcome variables from baseline to the two-year follow-up. Adjustments were done for age, gender, the oblique physical summary score of the SF-36 and the initial outcome scores. Results: The mean body mass index was 51.9 (SD, 7.5) before surgery and 31.8 (SD, 5.6) after two years $(\mathrm{P}<0.001)$. One patient reported $\mathrm{BD}$ before surgery. After two years 33 patients $(64.7 \%)$ reported BD, while 18 did not $(35.3 \%)$ The multiple regression analysis showed that having BD was associated with less change in the mental well-being score; $B,-15.4 ; 95 \% \mathrm{CI},-29.5$ to -1.3 $\mathrm{P}=0.033$. BD was however not associated with less change in the social functioning score; $B,-6.7 ; 95 \% \mathrm{CI},-23.4$ to $9.9 ; \mathrm{P}=0.416$, compared to patients not reporting BD. Conclusion: BD was common after DS and was associated with less improvement in the mental well-being score but not in the social functioning score. The overall effect of DS seems however to be good also in patients reporting $\mathrm{BD}$.

Conflict of interest: None.

Funding: The first author has received grant from Sogn og Fjordane University College.

\section{OP31}

\section{Bone Health after Biliopancreatic Diversion with Duodenal} Switch

McKenna, J.H.; Warmbrodt, N.S.; Halse, J.; Tonstad, S.

\section{Ullevål University Hospital, Oslo, Norway}

Aim: Biliopancreatic bypass with duodenal switch (BPD-DS) potentially leads to the largest weight loss compared to other treatments for obesity. We examined determinants of bone health after BPD-DS. Methods: All patients followed at the Preventive Cardiology outpatient clinic at least 2 years and up to 5 years after BPD-DS were invited. Blood parameters and bone mineral density (BMD) assessed by DXA were measured from Nov 2006 until May 2007. Results: Of 76 eligible patients, 55 women and 10 men took part of which 57 completed DXA measurements. Mean age was 40 years. Mean BMI was $51 \mathrm{~kg} / \mathrm{m}^{2}$ pre-surgery and $30 \mathrm{~kg} / \mathrm{m}^{2}$ post-surgery. Elevated serum Cterminal telopeptide of type I collagen (I-CTP) concentration was identified in $44 \%$ of cases and $66 \%$ had vitamin A concentrations below the reference range. Also, other markers of nutritional status were reduced. Mean BMD was within the normal range, but $25-32 \%$ had z-score measurements $<$ minus 1.0 SD of age-matched controls at the various sites. Patients with low BMD tended to be older, have lower BMI pre-surgery and lost less weight after surgery. Total body and dual femur bone densities and I-CTP concentrations were positively correlated with BMI reduction after control for age and common channel length $(\mathrm{p}<0.05)$. Conclusion: $\mathrm{I}-\mathrm{CTP}$ was increased in almost one-half, indicating increased bone turnover. Degree of weight loss per se was not associated with low BMD, but was associated with elevated I-CTP in the short term following BPD-DS. This may signify a greater risk of osteopenia and osteoporosis in the long term.

\section{OP32}

\section{Severe Postprandial Hypoglycemia Following Duodenal Switch}

Frigstad, S.O.; Aasheim, E.T.; Søvik, T.T.; Schou, C.F.; Konopski, Z.; Haukeland, J.W.

Oslo University Hospital Aker, Oslo, Norway

Purpose: Postprandial hypoglycaemia has been reported after gastric bypass surgery, but to our knowledge has not been described after duodenal switch. Methods: We present a 42-year-old woman who developed severe symptomatic postprandial hypoglycaemia 26 months after duodenal switch. Results: The patient's body mass index was reduced from 59 to $26 \mathrm{~kg} / \mathrm{m}^{2}$ the first year after surgery. After an uncomplicated cholecystectomy due to symptomatic choledocholithiasis, she developed liver failure. Following a period of severe malnutrition, she required nutritional support with total parenteral nutrition. Liver biopsy revealed cirrhosis. Her condition was stabilised after increased energy intake and vitamin supplementation. The patient was hospitalised after an acute episode of tremor, palpitations and impaired consciouisness 26 months after the first operation. The blood glucose level was $1.7 \mathrm{mmol} /$ L. Several episodes of symptomatic hypoglycaemia occurred 1-2 hours after meals. A standard oral glucose tolerance test showed a significant rise in insulin with a peak level after 60 minutes followed by a symptomatic episode of hypoglycaemia with the lowest blood glucose level after 120 minutes. Insulin and glucose levels were stable during fasting. After prescribing a diet low in simple carbohydrates, no significant decrease in blood glucose or symptomatic hypoglycaemia was observed. Conclusions: Postprandial hypoglycaemia can occur after duodenal switch. Suggested mechanisms for the increased insulin response leading to hypoglycaemia in some patients after bariatric surgery include increased incretin response, pancreatic beta cell hyperplasia (nesidioblastosis) and change in insulin sensitivity after weight reduction. Reduced gluconeogenesis and pathological insulin metabolism in the liver due to liver cirrhosis may have contributed in the present report. A diet low in simple carbohydrates may normalise the postprandial insulin response and improve the condition.

Conflicts of interest: None.

Funding: None.

\section{OP33}

\section{Significantly Altered Systemic Exposure of Atorvastatin} Following Biliopancreatic Diversion with Duodenal Switch in Morbidly Obese Patients

Stormark, K. ${ }^{1}$; Skottheim, I.B. ${ }^{2}$; Jakobsen, G.S. ${ }^{1}$; Christensen, H. $^{2}$; Jenssen, $T^{3,4}$; Åsberg, A. ${ }^{2}$; Hjelmesæth, J. ; Sandbu, $R^{1}$

${ }^{1}$ Morbid Obesity Centre, Vestfold Hospital Trust, Norway.

${ }^{2}$ School of Pharmacy, University of Oslo, Norway.

${ }^{3}$ Medical Department, Rikshospitalet Medical Centre, University of Oslo, Norway.

${ }^{4}$ Institute of Clinical Medicine, University of Troms $\varnothing$, Norway.

Purpose: The biliopancreatic diversion with duodenal switch (BPD/DS) is a surgical combined restrictive and malabsorptive weight-loss procedure. The purpose of the present study was to examine the impact of BPD/DS on possible changes in atorvastatin pharmacokinetics after surgery. Methods: Atorvastatin pharmacokinetics was investigated in ten morbidly obese patients treated with a daily dose of $20-80 \mathrm{mg}$ atorvastatin. Eight hour pharmacokinetic investigations were performed the day before and median (range) six (4-8) weeks after surgery. Results: The bioavailability of atorvastatin increased in nine out of ten patients between baseline and follow-up. On average, a 2-fold increase of the atorvastatin acid systemic exposure $\left(\mathrm{AUC}_{(0-8)}\right.$ ratio range $1.0-4.2, \mathrm{p}=0.001)$ was observed. The $\mathrm{C}_{\max }$-ratio increased 2 -fold (range $0.5-6.2, \mathrm{p}=0.04$ ) and $\mathrm{t}_{\max }$ increased from 1.2 hours before surgery to 2.3 hours after surgery $(\mathrm{p}=0.03)$. Conclusion: The present study indicates that BPD/DS is associated with increased bioavailability of atorvastatin in the majority of patients. Thus, re-titration down to lowest effective dose might be wise after this surgical procedure.

Conflicts of interest: None.

Funding: Rune Sandbu has received a grant from Vestfold Hospital Trust 
OP34

\section{Patient Involvement in a Software Development Project}

\section{- Developing an Electronic Diary}

\section{Rising, $S$.}

SSR, Oslo University Hospital. sturlari@online.no

Introduction: Lifestyle diseases like obesity are a growing problem. Information and communication technology (ICT) could be instrumental in patient empowerment. In design, also of software, user driven or participatory design methods of innovation have been promising. By the combination of ICT, patient empowerment- and user-driven-methodologies, there are potentials for distributing high quality health care. The current maturation state of Interne based software is named WEB 2.0. A WEB 2.0 application will enhance its value for the user when being used. Materials and Methods: As a part of the Morbid Obesity Center in Norway's South-Eastern Regional Health Authority program against obesity, our hospital takes care of a branch of patients who are given exercise and nutritional advice. The patients participated in focus-group interaction, and through semi-structured interviews. At all stage of the project video-observation was employed. Following the conceptual process, Use Case diagrams were made. Testing of the paper prototype was recorded on video. From these videos a specification was made and used as starting point for the technical development. The prototype has been tested using Camtasia, TechSmith, to capture the data. Results: Special attention has to be given to make the patients feel secure and comfortable in this new role as 'expert'. In the paper based usability testing there were no major difference between patients and staff. There was no time difference in the usability testing of the electronic prototype between patients - that had fewer errors - and therapists. When questioned the patients all said participating was a good experience and the idea of being part of the development felt good. Discussion: The innovation potential of patients about solutions for everyday problems with the aid of technology has to be evoked. In the current project standard techniques for interaction with users have been used, but modified under the influence of 30 years of personal clinical experience, which was instrumental in evoking the 'innovation potential' and run the focus group sessions in non-professional settings. Bringing patients in to the development cycle of health related software enables empowerment and engagement and has the possibility to enhance the delivery of healthcare.

Conflicts of interest: None.

Funding: Helsedialog and Innovation Norge. 
Aas, A.M. OP29

Aasheim, E.T. OP07, OP32

Aasprang, A. OP30

Ahlström, G. OP19

Al-Ansari, U. OP08

Andersen, J.M. OP06

Andersen, J.R. OP27, OP30

Andersen, L.F. OP09, OP10

Åsberg, A. OP33

Aschim, E.L. OP06

Bechensteen, B. OP09

Benth, J.S. OP09

Birketvedt, G.S. OP22

Bjørge, B. OP21

Blundell, J.E. OP14

Bø, K. OP11

B $\varnothing$, R.L. OP29

Christensen, H. OP33

Dinh, K.N. OP15

Drapkina, O.M. OP04

Ericson, U. OP12

Fismen, E. OP25

Florholmen, J. OP22

Fogelholm, M. RS3

Fon, H.O. OP15

Fredheim, J.M. OP01

Freeland-Graves, J.H. OP18

Frigstad, S.O. OP32

Gade, H. OP20

Gjevestad, E. OP15

Gjevestad, E. OP26

Graff-Iversen, S. OP09

Gullberg, B. OP12

Haakstad, L.A.H. OP11

Hager, H. OP02, OP03

Halse, J. OP31

Hansson, L.M. OP19

Hanvold, S. OP29
Hartmann, A. OP02

Haugen, F. OP17

Haugen, T.B. OP06

Haugstvedt, K.T.S. OP09

Haukeland, J.W. OP32

Heggen, E. OP17

Heitmann, B.L. RS2

Hjellset, V.T. OP21

Hjelmesæth, J. OP01, OP02, OP03, OP06, OP07, OP15, OP20, OP23, OP26, OP33

Hofs $\varnothing$, D. OP01, OP02, OP03, OP07, OP15, OP23

Holmboe-Ottesen, G. OP21

Holme, I. OP05, OP16, OP17

Holmen, J. RS1

Holven, K. OP28

Holven, K.B. OP07

Hussain, A. OP21

Jakobsen, G.S. OP23, OP33

Jenssen, T.' OP03, OP33

Johnson, L.K. OP07

Joner, G. OP10, OP13

Karlsson, T. OP24

King, N.A. OP14

Kjelstrup, L.S. OP27

Klemsdal, T.O. OP05, OP16, OP17

Konopski, Z. OP32

Korneeva, O.N. OP04

Krokstad, S. RS1

Kulseng, B. OP14

Kulseng, B.E. OP27

Lantz, H. OP24

Larsen, M.A. OP22

Larsson, I. OP24

Lee, J. OP18

Lekhal, S. OP22

Lien, A.G. OP25
Lindström, J. RS6

Lingaas Holmen, T. RS1

Lissner, L. OP08

Mæhlum, S. OP26

Martins, C. OP14

Mattingsdal, M. OP13

Maximo, I. OP18

McKenna, J.H. OP31

Midthjell, K. RS1

Moraeus, L. OP08

Mostad, I.L. OP27

Nafstad, I.T. OP09

Näslund, E. RS9

Natvig, G.K. OP30

Nordstrand, N. OP02, OP15

Olbers, T. RS10

Olsen, K. OP26

Oppedal, B. OP07

Orho-Melander, M. OP12

Ottestad, I. OP28

Pedersen, T.R. OP05, OP16, OP17

Pepper, M.R. OP18

Pietiläinen, K. RS4

Pollestad Kolsgaard,

M.L. OP10, OP13

Poortvliet, E. OP08

Refsum, H. OP29

Retterstøl, K. OP28

Retterst $\varnothing I$, L. OP13

Rising, S. OP34

Robertson, L. OP25

Røislien, J. OP02, OP03, OP23

Rollheim, J. OP01

Roos, C. OP12

Saltvedt, E. OP15

Sandbu, R. OP06, OP15, OP23, OP33
Saxegaard, K. OP09

Schou, C.F. OP32

Sjöberg, A. OP08

Skottheim, I.B. OP33

Skram, I.V. OP06

Smedstad, L.M. OP26

Sonestedt, E. OP12

Søvik, T.T. RS11, OP32

Stenlöf, K. OP24

Stormark, K. OP33

Strøm, E.C. OP28

Strømmen, M. OP27

Svendsen, M. OP05

Tanbo, T. OP07

Tangen, K. OP28

Tonstad, S. RS8, OP05, OP10, OP13, OP16, OP17, OP31

Undlien, D. OP13

Våge, V. OP30

van Roy, B. OP09

Vegsgaard, K.M. OP01

Vogt, H. OP09

Wandel, M. OP21

Wangensteen, T. OP13

Warmbrodt, N.S. OP31

Windju, S. OP06

Wirfält, E. OP12

Witczak, O. OP06

Xu, B. OP18

Yngve, A. OP08

Zhu, Y. OP18

\section{KARGER}

Fax +49761 4520714

Information@Karger.de

www.karger.com 